\title{
Sex-Dependent Expression and Fitness Consequences of Sunlight-Derived Color Phenotypes
}

\author{
Juan A. Fargallo, ${ }^{1, *}$ Félix Martínez, ${ }^{2}$ Kazumasa Wakamatsu, ${ }^{3}$ David Serrano, ${ }^{4}$ \\ and Guillermo Blanco ${ }^{1}$
}

1. Departamento de Ecología Evolutiva, Museo Nacional de Ciencias Naturales-Consejo Superior de Investigaciones Científicas, José Gutiérrez Abascal 2, 28006 Madrid, Spain; 2. Sociedad para la Conservación de los Vertebrados, Avenida de los Pinos 17, 28914 Leganés, Madrid, Spain; 3. Department of Chemistry, Fujita Health University School of Health Sciences, Toyoake Aichi 470-1192, Japan; 4. Department of Conservation Biology, Estación Biológica de Doñana, Consejo Superior de Investigaciones Científicas, Américo Vespucio s/n, Isla La Cartuja E-41092 Sevilla, Spain

Submitted September 6, 2017; Accepted November 17, 2017; Electronically published March 22, 2018

Online enhancements: appendix. Dryad data: https://dx.doi.org/10.5061/dryad.nr2m3.

\begin{abstract}
AвSTRACT: To understand whether early phenotypes are adaptive, knowledge of the environmental factors involved in their variation and the derived benefits from their expression is needed. Temperature and sunlight are considered two major selective forces influencing phenotypic coloration of birds at a global scale. However, within-population color adaptations in response to sunlight temperature variation have been scarcely investigated, and their acclimatization capacity is currently unknown. In addition, the sexes differ in their sensitivity to environmental factors during growth. This study evaluates how melanin plumage coloration varies in relation to sex and sunlight exposure in developing griffon vultures Gyps fulvus and how this correlates with survival. The results show that individuals grown in nests more exposed to sunlight developed paler plumages, as predicted by the thermal melanism hypothesis. In addition, paler males - but not females - have lower survival probability. Finally, a significant sexual dichromatism in fledgling plumage was observed, with females being paler than males. These results reveal within-population color variation related to sunlight temperature conditions, probably as a capacity for local acclimatization through color plasticity, and also provide evidence of sex differences in fitness optima for this trait under ecological pressures.
\end{abstract}

Keywords: melanin-based coloration, sexual dimorphism, survival, Gyps fulvus.

\section{Introduction}

Environmental conditions experienced during development often imply changes in phenotype that, in turn, have consequences on fitness (Lindström 1999; Monaghan 2008). Phenotypic changes observed within a single genotype can be de-

\footnotetext{
* Corresponding author; e-mail: fargallo@mncn.csic.es. ORCIDs: Fargallo, http://orcid.org/0000-0003-4090-9000; Wakamatsu, http:// orcid.org/0000-0003-1748-9001.

Am. Nat. 2018. Vol. 191, pp. 726-743. (C) 2018 by The University of Chicago. 0003-0147/2018/19106-57938\$15.00. All rights reserved.

DOI: $10.1086 / 697218$
}

termined by the ability of organisms to adjust physiological, morphological, or behavioral traits to prevailing environmental conditions. This capacity is called phenotypic flexibility, acclimation, or acclimatization when phenotypic changes are reversible and phenotypic plasticity or developmental plasticity when they are not (Piersma and Drent 2003; West-Eberhard 2003). Trait plasticity is considered to be adaptive, allowing organisms to compensate for environmental changes to maintain fitness under environmental heterogeneity (West-Eberhard 2003; Gómez-Mestre and Jovani 2013). A phenotype-environment mismatch is considered the intrinsic fitness cost of lack of plasticity (Piersma and Drent 2003; Auld et al. 2010; Beaman et al. 2016).

Animals are particularly sensitive to external conditions during development, a phase in which tissues and organs differentiate. During this phase, environmental cues may induce different developmental pathways, making phenotypic changes difficult to revert, thus explaining why phenotypic plasticity is mainly restricted to this early stage of life (Witte et al. 1990; Wilson and Franklin 2002; Bateson et al. 2004). However, when environmental conditions exceed a certain range of change, organisms may experience phenotypic changes to mitigate the detrimental effect of the environment. These changes may even be the product of stressful situations, resulting in damaging effects or decreases in fitness (Wilson and Franklin 2002; Monaghan 2008). Phenotypes derived from stressful environmental conditions may confound the expected beneficial effects of acclimatization or developmental plasticity (Wilson and Franklin 2002). To understand the influence of early phenotypes on life-history evolution, it is essential to know how much the expression of a trait in response to developmental conditions varies with respect to the optimal expression providing fitness benefits.

Embryonic development in most oviparous species as well as postnatal development in altricial birds consists of immo- 
bile life-history stages and is thus greatly subject to the microclimatic conditions of the nest. Solar radiation-induced temperature is one of the most influential environmental factors affecting developmental programs, trait expression variation, and survival prospects (Angilletta et al. 2010; Telemeco 2014; Beaman et al. 2016). Oviparous species have developed parental strategies focused on providing optimal thermal conditions to oviposition and nesting sites (e.g., Grant 1982; Jackson et al. 1989; Skolbekken and Utne-Palm 2001; Jones et al. 2004; Angilletta et al. 2009) as well as the capacity of thermal acclimatization at developmental stages (Wilson and Franklin 2002; Angilletta et al. 2010; Beaman et al. 2016). Much of what is known about the costs and benefits of the morphological and physiological phenotypic response to temperature gradients comes from lab studies in ectotherm species (Wilson and Franklin 2002; Beaman et al. 2016). Lab conditions are essential to analyze phenotypic responses to specific manipulated environmental variables. Nonetheless, this approach has less capacity to analyze phenotype-related fitness benefits because it is not possible to incorporate all of the factors that are important for survival and reproduction in natural conditions, particularly in long-lived vertebrates with delayed maturity and high movement abilities. Furthermore, artificial lab conditions often create stressful scenarios that confound the fitness predictions assigned to the phenotypes (Wilson and Franklin 2002; Kristensen et al. 2008; Boonstra 2013).

Endotherms have internal mechanisms for body thermoregulation that help maintain thermal homeostasis over a wide range of ambient temperatures. Thus, the study of the phenotypic response to temperature changes in this group (mainly in birds and mammals) has predominantly focused on the physiological processes underlying thermoregulatory responses (Boyles et al. 2011). Growing concerns of nature conservation under global warming conditions has led to the study of the effect of temperature on organisms, including endotherms, although this research has focused on how thermal tolerance predicts species distribution according to ambient climatic variability (see Khaliq et al. 2014). However, the role of morphological or external traits of body temperature regulation in endotherms and the timescale of change as well as its relationship with fitness in natural populations remain relatively unknown.

Coloration is one of the most diverse phenotypic traits in nature, and its function is one of the most studied subjects in evolutionary ecology, particularly in social and sexual selection contexts (Hill and McGraw 2006; Bradbury and Vehrencamp 2011). Studies exploring the function of animal coloration have primarily focused on the adult stages of organisms, while the role of phenotypic coloration obtained during development in fitness has been less investigated (Palma and Steneck 2001; Berggren et al. 2004; Hubbard et al. 2015). Thermoregulation through the absorption/reflection of solar radiation is one of the adaptive functions in animal colora- tion (Walsberg et al. 1978; Angilletta et al. 2010), particularly for melanin-based coloration (Watt 1968; Clusella-Trullas et al. 2008). Melanin-based pigmentation confers coloration in a broad range of organisms and the biochemistry of melanin synthesis is highly conserved across different taxonomic groups (Bagnara et al. 1979; Hoekstra 2006; Wittkopp and Beldade 2009). A strong genetic basis for melanin-based coloration has been established for both discrete color morphs and the expression of continuous characters (Wittkopp and Beldade 2009; Hubbard et al. 2010; McKinnon and Pierotti 2010). In the case of birds, different environmental sources of variation in melanic coloration have been reported, including conditions of food and nutrition (Poston et al. 2005; Fargallo et al. 2007a; McGraw 2007), stress hormones (Fargallo et al. 2007b), reproduction (Griffith 2000), and parasite infestation (Fitze and Richner 2002). This color system is considered a good model for studying the genetic mechanisms that determine phenotypes and adaptive coloration (Mundy 2005; Hubbard et al. 2010).

Melanin-based color changes in the dermis, cuticle, and scales of ectotherms in response to temperature variations are considered a thermoregulatory mechanism through the absorption or reflection of solar radiation (Clusella-Trullas et al. 2008; Tattersall et al. 2012). This function is not as evident in the case of feathers and fur in birds and mammals. First, it is not known whether there are sensitive physiological processes to produce color variation in growing feathers or fur induced by temperature-radiation changes. Second, the role of color in regulating body temperature in birds and mammals is not clear (see Walsberg and Wolf 1995; Caro 2005; Tattersall et al. 2012). Increases in body temperatures for darker-haired individuals have been recorded in some mammal species (e.g., West and Packer 2002; Hetem et al. 2009); however, it has also been suggested that a higher solar radiation absorption near the body surface in darker coats of mammals and birds may help reduce heat by conduction, convection, and radiation, thus creating an insulating layer or heat shield able to reduce body heat gain (see Tattersall et al. 2012). Consequently, it is difficult to predict a direction for coloration in response to solar radiation or temperature variation in these endotherm groups.

Geographical trends observed in coloration provide some clues about other potential environmental variables that modulate bird coloration and about possible acclimatization and/or adaptation to local climatic conditions. For example, Gloger's rule states that birds inhabiting more humid regions will be more darkly colored than those from more arid regions (Gloger 1833 in Zink and Remsen 1986). There are different explanations for this gradient. For instance, (1) darker individuals in colder humid habitats are expected to show faster heating rates and thus more efficient thermoregulation; (2) given that bacteria grow better in more humid environments and darker melanic feathers resist bacterial degra- 
dation better, darkening with humidity may be an adaptive response to resist bacterial degradation; or (3) individuals are better matched to their backgrounds (i.e., camouflaged) if they are dark in humid habitats and pale in arid habitats (Mosher and Henny 1976; Zink and Remsen 1986; Burtt and Ichida 2004; but see Walsberg et al. 1978).

The first of these explanations is the basis for the thermal melanism hypothesis, which predicts that melanism (darkening) plays an adaptive role in thermoregulation by allowing darker/paler individuals to absorb/reflect more solar radiation in cool/warm climatic regions (Watt 1968; ClusellaTrullas et al. 2008). However, many bird species inhabiting hot deserts are black or exhibit dark plumage (Ward et al. 2002), which contradicts both Gloger's rule and the thermal melanism hypothesis. In these cases, feather melanization is hypothesized to act as a shield to protect the inner organs from the strong ultraviolet radiation typical of deserts (Burtt 1986; Ward et al. 2002) because of melanin's capacity for ultraviolet absorption (Meredith and Sarna 2006). Nevertheless, it has also been suggested that the feather itself, regardless of the color, may be sufficiently protective against radiation (Porter 1967).

Solar radiation, mainly the ultraviolet fraction (280400 nanometers) of sunlight, may induce color changes in fur and feathers through physical and chemical changes of keratin and pigments (Blanco et al. 2005; Montgomerie 2006; Robbins 2012). The mechanisms generating color lightening or bleaching by the action of sunlight have been investigated mostly in wool and hair and are completely unknown for feathers. Physical changes in mammalian keratin that promote bleaching (whitening or yellowing) involve the degradation by photooxidative reactions of several amino acids in the keratin structure or the removal of the 18-methyleicosanoic acid that is covalently linked to the outer surface of all keratin fibers (Millington and Church 1997; for a review, see Robbins 2012). Little to nothing is known of the role of melanin pigments in hair or feather bleaching. Unlike the majority of natural pigments, melanins are complex polymers difficult to isolate and purify, and thus its structure is not well described (d'Ischia et al. 2013). However, several specific degradation products of alkaline hydrogen peroxide oxidation and hydriodic acid hydrolysis have been used as markers of melanin quantity and quality. Briefly, pyrrole-2,3,5-tricarboxylic acid (PTCA) is a specific degradation marker for eumelanin, 4-amino-3-hydroxyphenylalanine (4-AHP) for benzothiazinetype pheomelanin, and thiazole-2,4,5-tricarboxylic acid (TTCA) for benzothiazole-type pheomelanin (Ito et al. 2011). In addition, the total amount of melanin can be estimated spectrophotometrically (Ozeki et al. 1996). Recently, the chemical changes in these melanin markers that cause bleaching in human hair and mouse fur have been described (Wakamatsu et al. 2012). While total melanin did not change after aging or ultraviolet (UV)-induced treatments (except for red hair under UV radiation), the ratios of TTCA/4-AHP and TTCA/ PTCA increased drastically, indicating molecular changes in pheomelanin and eumelanin pigments by photo-induced oxidative degradation. Furthermore, UV radiation induced the conversion of the benzothiazine to the benzothiazole moiety in pheomelanin, for which TTCA increased at the expense of 4-AHP under UV-induced conditions. The same changes were also observed with synthetic soluble melanin (Wakamatsu et al. 2012).

Within-population genetic-based color variation or polymorphism has been used in classic studies of microevolution (Hoekstra 2006; Hubbard et al. 2015). Adaptations to heterogeneous climatic conditions, particularly temperature, account for some of this variation. Although the causal link between individual coloration and temperature is not well established, in some bird species, color variation seems to be maintained through differences in reproductive success (Sirkia et al. 2010) or viability (Karell et al. 2011) under different temperature conditions. Key to determining the expected phenotype (dark or pale) for sunny and hot environments is the study of the development of plumage coloration in a gradient of sunlight exposure. However, to date, there have not been any within-population studies analyzing color variation in relation to solar radiation or temperature gradients. Although abiotic factors, such as climatic ones, can predict the geographic distribution of bird color phenotypes, it is also important to know the capacity of individuals to adjust coloration to local environments and its associated fitness benefits in order to determine the plasticity of phenotypic traits and their potential for adaptation (Monaghan 2008).

Sex is also a source of phenotypic variation. Given their different reproductive roles and life histories, males and females show different phenotypes, with sexual dimorphism being the result of sex differences in optimum trait values under natural — and particularly sexual — selection pressures (Hedrick and Temeles 1989; Chenoweth et al. 2008). Sexually antagonistic selection (different selective optima for sexually shared traits) generates intralocus sexual conflict by moving the sexes from their phenotypic optima as a result of sexspecific selection on shared traits, with sexual dimorphism serving to resolve this conflict (Bonduriansky and Chenoweth 2009; Cox and Calsbeek 2009). Despite the importance of this for understanding natural selection and the evolution of sexual dimorphism, its occurrence has been scarcely investigated in wild populations (Bonduriansky and Chenoweth 2009; Cox and Calsbeek 2009; Tarka et al. 2014). Key to investigating sexual dimorphism is determining why a given sexually shared trait has two different fitness optima by identifying the components of fitness linked to the expression of the trait in each sex (Cox and Calsbeek 2009).

In this study, we investigated the potential influence of sunlight exposure and sex on plumage coloration during development in the nest and whether this color variation relates 
to fitness components in the griffon vulture Gyps fulvus, a uniparous, long-lived sexually monomorphic scavenger. We first measured plumage coloration in four cohorts of vulture fledglings in a breeding colony in the Mediterranean region, analyzed sexual differences, and determined melanin-based coloration in feathers. Second, we analyzed the relationship between the gradient of sunlight exposure on the nest and fledgling coloration. If vultures have the capacity to adjust their phenotype to environmental conditions during development, two alternative predictions can be made: individuals growing in nests that are more exposed to sunlight should be (1) lighter (paler) if thermoregulation is the dominant selective pressure (e.g., Hochscheid et al. 2002; Clusella-Trullas et al. 2008; Grémillet et al. 2012) or (2) darker if ultraviolet protection is the selective pressure underlying chick coloration (e.g., Bergman 1982; Burtt 1986). Furthermore, plumage color might change in relation to sunlight exposure as a consequence of radiation-induced bleaching. In this case, we would expect to observe (1) no significant correlation between feather lightness and pigment concentration if bleaching is due to physical or chemical changes in keratin or keratin-linked components; (2) no change in total melanin, increases in TTCA concentration, and increases in TTCA/4-AHP and TTCA/PTCA ratios as feather lightness increases if lightening is due to melanin photodegradation; and (3) paler plumage in fledglings that have spent more time exposed to sunlight (older fledglings), after controlling for sunlight exposure of the nest. Furthermore, if the variation of vulture coloration reflects individual adaptations (nesting behavior) to grow in different sunlight conditions, no difference in fitness along the gradient of sunlight exposure is predicted. However, if different sunlight conditions of the nest reflect nest-parent quality, a correlation would be expected between nest sunlight exposure and indicators of nest-parent quality, such as long-term fledgling productivity of the nest and laying date (with worst nests being those occupied at a later date by low-quality parents). Finally, we investigated whether coloration can promote different lifehistory trajectories between sexes by analyzing the relationship among sex, plumage coloration, and fitness. Because this species raises only one nestling in each breeding attempt, any confounding effects of within-brood sexual-size dimorphism and brood size (Carranza 2004; Jones et al. 2009) are avoided. As a key component of fitness, we analyzed survival and reproductive success during the subsequent 16 years after fledging.

\section{Material and Methods \\ Study Species and Study Area}

The griffon vulture is a heavy $(\sim 8-10 \mathrm{~kg})$, soaring obligate scavenger that lives in hilly areas throughout the Palearctic region. They are social at carcasses and breeding and roosting sites and produce only one egg during each breeding event (Donázar 1993). The species' phenotype does not apparently differ between sexes in plumage features or size but does with age. Fledglings show a general dark brown plumage with lanceolated body and ruff feathers, black bill and eye, and a head and neck covered with white down. Subadults become progressively paler in feather, bill, and eye color until acquiring the full adult appearance (at 5-6 years old), especially characterized by white and short ruff feathers (Elosegui 1989; Blanco and Martínez 1996). The nests are rough structures of branches and vegetation placed in cliff caves and ledges of variable size and coverage.

The study was conducted in the Hoces del Riaza Natural Park $\left(41^{\circ} 31^{\prime} \mathrm{N}, 3^{\circ} 36^{\prime} \mathrm{W}\right)$, north of Segovia Province, Spain. The climate of this region is supra-Mediterranean with cold winters and dry, warm summers. The study area includes a complex of cliffs and canyons where an increasing population of griffon vultures breeds at high densities (459 breeding pairs over $12 \mathrm{~km}$ of canyon in 2013). In the study area, the maximum mean daily temperature is $26.4^{\circ} \mathrm{C}$ from June to August, easily exceeding $40^{\circ} \mathrm{C}$ on some days. During these 3 months, about 45 days on average exceed $30^{\circ} \mathrm{C}$ (Cano 1990). Vultures in the study area are currently highly dependent on livestock carrion found at carcass dumps provided by stabled livestock operations, mostly of swine (Blanco 2014).

\section{Fieldwork Procedures}

Regular and intensive monitoring involving five complete surveys of the colony each year was conducted throughout the breeding season to detect all pairs (Martínez et al. 1997) and to determine whether the pairs laid (breeding pairs) or not (nonbreeding pairs). Nonbreeding pairs were identified on the basis of typical pair-bonding behavior, including close contact, nest building and defense, and copulation (Blanco et al. 1997). We observed at a distance the presence of eggs in the nests, recorded the start of incubation, and calculated the date of hatching on the basis of nestling age (Elosegui 1989). All of these criteria considering a 55-day incubation period were assessed to determine laying dates within 10-day periods from December 10 onward (Martínez et al. 1998). Nests were regularly checked to verify breeding failure or the success of each pair in fledging young; young fledged from June to August. These observations were made by telescope at distances that avoided disturbance of the birds in the colony.

When nestlings were 60-80 days old, we accessed their nests by climbing. From 1990 to 2014, nestlings $(n=428)$ in the study colony were banded with metal and polyvinyl chloride (PVC) rings with three alphanumeric characters forming a unique code than could be read at long distances using terrestrial telescopes. In addition, we banded nestlings 
$(n=100)$ in other colonies in the Segovia and Avila provinces in central Spain. A drop of blood was collected to sex individuals using standard molecular procedures (Wink et al. 1998).

During the entire study period, we intensively searched for individual banded birds with PVC rings by means of 10 20 visits (depending on the year) to the colony during the breeding season, including at least five complete surveys of the breeding population. These data were complemented with information on banded individuals recorded by rangers and amateur observers. Nest quality was determined by nest productivity - that is, the total number of fledglings produced in each nest - over 20 years (from 1992 to 2011). The more fledglings a nest produced, the higher its quality.

\section{Nest Sunlight Exposure and Orientation}

During nest access, we recorded the cavity nest dimensions with a tape measure. Nest exposure to solar radiation (hereafter sunlight exposure) was represented by the acute angle of a right triangle whose right-angle vertex was approximately at the vertical of the most external ceiling border of the nest cavity. The length of the horizontal side corresponds to distance from the nest center to the right-angle vertex, while the vertical side corresponds to the cavity height at the most external ceiling border (i.e., from the right-angle vertex to the ceiling border). Thus, the exposure angle was calculated as $\mathrm{EA}=\sin ^{-1}$ (cavity height/hypotenuse). When the nest was located on an open ledge without a ceiling and at a variable but generally short distance from the vertical wall of the cliff, we assumed a maximum exposure angle of $90^{\circ}$. Sunlight exposure in degrees was converted to radians for statistical analyses. Nest orientation was determined using a magnetic compass to record the direction of an imaginary line perpendicular to the cliff wall where the nest was located.

\section{Plumage Coloration}

Fledgling plumage color was visually scored at the nest and later with telescopes in July 1996-1999 using a color scale with five categories of brown color intensity, ranging from dark brown (color score $=1$ ) to pale brown (color score $=$ 5 ). The brown color scale was based on interindividual variation of feather color on the back and wings, excluding black remiges (fig. 1).

Color scores were recorded just before the nestling fledged at an average age of $111.8 \pm 12.5$ days after hatching, ranging from 82 to 137 days. At this stage, fledglings remained standing for long time periods in their natal eyries, generally in or close to the nest location, waiting to be fed by their parents. This allowed us to score the general color on the back and wing during the morning daylight while avoiding direct sunlight exposure. Plumage color was scored for a total of 100 sexed fledglings from 51 different nesting sites over four consecutive years (1996-1999). Color scores were repeatable between independent observers (Spearman rank correlation, $r_{s}=0.94, P<.001, n=33$ ) and between the nest stage (scored in July just before fledging) and two months later (scored in September as juveniles after fledging) for a sample of banded individuals in each year (1996: $r_{s}=0.93, P<.001, n=16 ; 1997: r_{s}=0.97, P<$ $.001, n=12 ; 1998: r_{s}=0.81, P=.003, n=11 ; 1999$ : $\left.r_{s}=0.87, P<.001, n=16\right)$. Both visual color estimations (July and September) of these 55 individuals were used to analyze whether potential color change was correlated with the time of exposure to sunlight. For this purpose, color difference and time elapsed (days) from the first to the second visual color estimation were calculated.

\section{Coloration and Melanin Composition in Feathers}

To determine the reliability of visual color scores, 17 feathers (lesser wing covers) collected from 17 vulture chicks at the age of 60-80 days in the study area were visually scored by G.B., and the color was measured by J.A.F. with a spectrophotometer (CM-2600d Konica Minolta, Tokyo), taking four measurements from four different points, two in each vane of each feather. Plumage coloration for each feather was calculated as the mean value of the four color measurements. Reflectance spectra are shown in figure A1 (figs. A1A4 are available online). We used the $\mathrm{L}^{*} \mathrm{a}^{*} \mathrm{~b}^{*}$ color space, where $\mathrm{L}^{*}$ indicates lightness and $\mathrm{a}^{*}$ and $\mathrm{b}^{*}$ indicate the chromaticity coordinates. The saturation of the color given by the coordinates $\mathrm{a}^{*}$ and $\mathrm{b}^{*}$ increases as the absolute values of both coordinates increase (Montgomerie 2006). Only the $\mathrm{L}^{*}$ and $\mathrm{a}^{*}$ axes (coordinate varying from red to green and including brown) were used as lightness and chromatic color components.

In these 17 feathers, melanin composition and concentration were also measured. Pheomelanin and eumelanin concentration was estimated as described by Wakamatsu et al. (2002) and Ito et al. (2011). High-performance liquid chromatography (HPLC) was used to quantify eumelanin and pheomelanin contents through specific degradation products, 4-AHP by reductive hydrolysis of pheomelanin with hydriodic acid (Wakamatsu et al. 2002) and PTCA and TTCA by alkaline $\mathrm{H}_{2} \mathrm{O}_{2}$ oxidation of eumelanin and pheomelanin, respectively (Ito et al. 2011). Briefly, 12-15 mg of feather were cut and homogenized with a glass homogenizer in water $(10 \mathrm{mg} / \mathrm{mL})$. Sample homogenate $(100 \mu \mathrm{L})$ was placed into a 10-mL screw-capped (Teflon) conical glass test tube, to which $375 \mu \mathrm{L}$ of $1 \mathrm{~mol} / \mathrm{L} \mathrm{K}_{2} \mathrm{CO}_{3}$ and $25 \mu \mathrm{L}$ of $30 \% \mathrm{H}_{2} \mathrm{O}_{2}$ (final concentration: $1.5 \%)$ were added. The mixture was mixed vigorously at $25^{\circ} \mathrm{C} \pm 1^{\circ} \mathrm{C}$ for $20 \mathrm{~h}$. The residual $\mathrm{H}_{2} \mathrm{O}_{2}$ was decomposed by adding $50 \mu \mathrm{L}$ of $10 \% \mathrm{Na}_{2} \mathrm{SO}_{3}$; the mixture was 


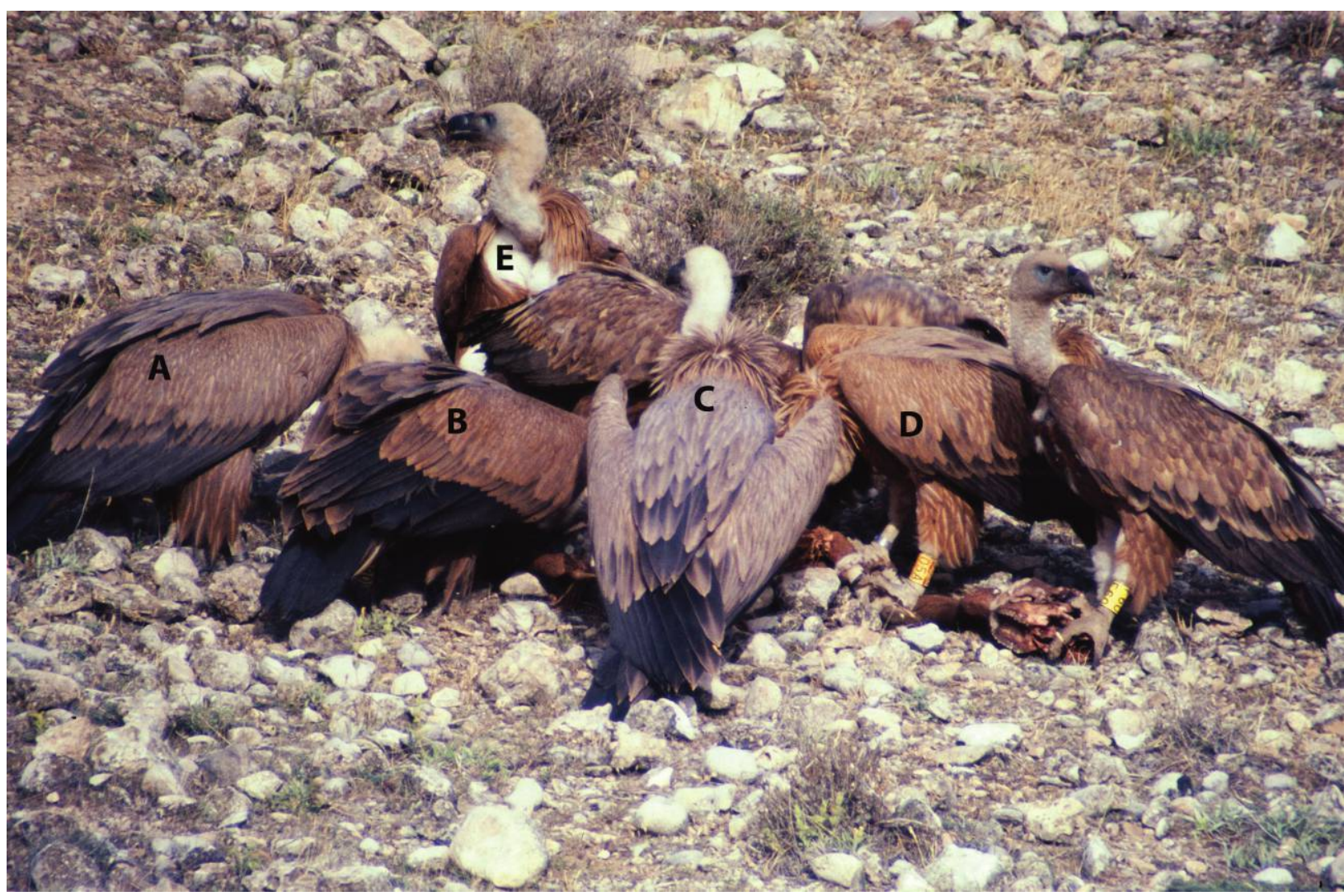

Figure 1: Picture of wild griffon vultures Gyps fulvus in the study area showing the variation in fledgling plumage coloration (photo taken in August 1992) from paler $(C, D)$ to darker $(A, B, E)$ brown. The three individuals without letters are second-year vultures. Photo credit: A. Gómez.

then acidified with $140 \mu \mathrm{L}$ of $6 \mathrm{~mol} / \mathrm{L} \mathrm{HCl}$. After vortexing, the reaction mixture was transferred to 1.5 -mL Eppendorf tubes and centrifuged at 4,000 $\mathrm{g}$ for $1 \mathrm{~min}$, and an aliquot $(80 \mu \mathrm{L})$ of the supernatant was directly injected into the HPLC system with UV-VIS detector (269 nm; Ito et al. 2011). For the determination of 4-AHP, sample homogenate $(100 \mu \mathrm{L})$ was put into a $10-\mathrm{mL}$ screw-capped conical test tube, to which $20 \mu \mathrm{L}$ of $50 \% \mathrm{H}_{3} \mathrm{PO}_{2}$ and $500 \mu \mathrm{L}$ of $57 \%$ hydriodic acid were added. The tube was heated at $130^{\circ} \mathrm{C}$ for $20 \mathrm{~h}$, after which the mixture was cooled. An aliquot (100 $\mu \mathrm{L})$ of each hydrolysate was transferred to a test tube and evaporated to dryness using a vacuum pump connected to a dry ice-cooled vacuum trap and two filter flasks containing $\mathrm{NaOH}$ pellets. The residue was dissolved in $200 \mu \mathrm{L}$ of $0.1 \mathrm{~mol} / \mathrm{L} \mathrm{HCl}$. An aliquot (10$20 \mu \mathrm{L}$ ) of each solution was analyzed on the HPLC system with electrochemical detection ( $+600 \mathrm{mV}$ vs. an $\mathrm{Ag} / \mathrm{AgCl}$ reference electrode). Eumelanin (EM) content was estimated using a conversion factor of 63 for PTCA because PTCA yield from this eumelanin was calculated to be $16 \mu \mathrm{g} / \mathrm{mg}$ (Ito et al. 2011). For the conversion of TTCA in benzothiazol-type pheomelanin (BZ-PM) and 4-AHP in benzothiazine-type pheomelanin (BT-PM), we used factors of 34 (Ito et al. 2011) and 6.8, respectively (this study, on the basis of the 4-AHP yield of $148 \mu \mathrm{g} / \mathrm{mg}$ from synthetic dopa + cys-pheomelanin; d'Ischia et al. 2013). As a measure of total melanin, we used an absorbance at $500 \mathrm{~nm}$ after solubilization in aqueous Soluene-350, as described by Ozeki et al. (1996).

\section{Fitness Components}

Seventy-one out of 100 fledglings from the four cohorts (1996-1999) we worked with returned to their natal colony. Individuals returned at ages ranging from 1 to 14 years old (mean $3.4 \pm 3.2$ years, $n=71$ ). Survival was estimated using local annual survival of individuals in capture-markrecapture (CMR) models during the first 16 years of life. Return probability (and therefore local survival) is considered a good estimator of survival, given that griffon vultures show high natal philopatry. None of these 100 individuals were observed breeding in a different colony in Spain, and only one of the 71 recruited individuals moved to a different eyrie after breeding in a particular eyrie for five years (F. Martínez and G. Blanco, unpublished data). As a measurement of reproductive success, we calculated the 16 -year offspring pro- 
duction, determined as the number of offspring that a given individual produced during the first 16 years of life. Survival and 16-year offspring production were analyzed for the four cohorts born from 1996 to 1999.

\section{Statistical Procedures}

To assess whether nest quality depended on sunlight exposure, a generalized linear model (GLM; Poisson error, log function) was constructed including 20-year fledgling productivity of the study nests in the colony (count variable) as a dependent variable and sunlight exposure as the predictor variable. Plumage color variation (interval variable) in relation to sunlight exposure was analyzed using a linear mixed model (LMM) in which sunlight exposure, sex, age, and nest quality (20-year fledgling productivity) were considered as predictor variables. Along with sex, year was also included as a fixed factor in order to explore its interaction with predictor variables. Nesting site was included as a random factor and laying date as a covariate. Pairwise interactions were tested. We used Akaike's information criterion corrected for small sample size (AICc) for model selection. The best model was the one with the lowest AICc value with a difference $(\Delta \mathrm{AICc})>2$ from the second-best model. Models were considered equally parsimonious if the difference in AICc from the best-supported model was $\leq 2$. Analyses were two-tailed and were conducted in R statistical software. We used lme4 (Bates et al. 2015) and MuMIn (multi-model inference) for model selection based on AIC (Barton 2016). Circular statistics (linear-circular correlation test) in Oriana 4.02 statistical software (Kovach 2011) were used to analyze the relationship between plumage color and nest orientation in the vulture colony. Differences in visual color estimations between July and September were observed in 14 out of 55 individuals. In all 14 cases, the observed color scores increased by 1 ; thus, the variable color difference showed values of only 0 (no difference) and 1 (increase). For this reason, a GLM (binomial error, logit function) was used to analyze color difference in relation to both time elapsed from the first (July) to the second (September) visual color estimations and sunlight exposure.

We used CMR models as implemented in the program MARK v. 8.1 to estimate the effect of fledgling plumage coloration on apparent survival probability (White and Burnham 1999). In a first step, we constructed CMR models in which survival $(\phi)$ and reencounter $(p)$ were allowed to vary with time, cohort, age, and sex. However, models with time or full age resulted in a high number of extrinsically nonidentifiable parameters; therefore, we started from a reduced general model with sex $(s)$, cohort $(c)$, and four biologically sensible age classes $(a 1, a 2, a 3-5$, and $a 6$ for birds of ages $1,2,3-5$ and $>5$ years, respectively). Goodness of fit of this general model was assessed by generating 1,000 bootstrap samples fulfilling the assumptions of independence and no heterogeneity. Model fit was calculated as (sim - rank)/sim, where sim is the number of simulations and rank is the rank of the observed deviance of the general model within the expected distribution of bootstrap samples (Cooch and White 2016). We constructed constrained versions of the general model that reduced the number of parameters by comparing models with different age structure specifications and/or assuming that $\phi$ or $p$ were constant among cohorts or between sexes. In a second step, we constructed another sequence of models that started with the best-supported models from the first step and incorporated plumage coloration as an individual covariate (Cooch and White 2016). Model selection (relative model fit) was assessed using sample size-adjusted AIC corrected for overdispersion (QAICc; see Burnham and Anderson 2002). The variance inflation factor was calculated by dividing the observed $\hat{c}$ by the mean expected $\hat{c}$ from the 1,000 bootstrap samples. Models were considered equally parsimonious if the difference in QAICc ( $\triangle$ QAICc) from the best-supported model was $\leq 2$. To cope with model selection uncertainty, model averaging was used (Burnham and Anderson 2002; Cade 2015). Statistical procedures for 16-year offspring production are described in the appendix, available online. Data are deposited in the Dryad Digital Repository: https://dx.doi.org/10.5061/dryad.nr2m3 (Fargallo et al. 2018).

\section{Results}

\section{Melanin Concentration and Feather Coloration}

The melanin pigmentation of vulture feathers was composed of EM (mean concentration $8.9 \pm 2.9 \mu \mathrm{g} / \mathrm{mg}$ ) and two types of pheomelanin (PM): benzothiazine (BT-PM; mean concentration $4.4 \pm 1.2 \mu \mathrm{g} / \mathrm{mg}$ ) and benzothiazole (BZ-PM; mean concentration $9.1 \pm 2.0 \mu \mathrm{g} / \mathrm{mg}$ ). EM was significantly and positively correlated with BZ-PM $\left(r_{s}=0.80, P<.001\right.$, $n=17)$. No significant correlations were found between EM and BT-PM or BZ-PM and BT-PM (both $P>.72$ ).

Visual color score was closely correlated with spectrophotometer color measurements of lightness $\left(r_{s}=0.86, P<\right.$ $.001, n=17)$ and chromatic $\left(r_{s}=0.58, P=.015, n=\right.$ 17) components. Lightness was significantly explained by EM and BZ-PM content in feathers, with paler feathers having lower concentrations of EM and BZ-PM (table 1). The chromatic component was similarly significantly correlated with both EM and BZ-PM content (table 1). Also, visual color score was significantly and negatively correlated with both EM and BZ-PM feather content (table 1). The concentration of BT-PM in feathers was not significantly correlated with any color component or visual color score. Also, visual color score, lightness, and the chromatic component were negatively correlated with the total sum of melanin pigment concentrations $(\mathrm{EM}+\mathrm{BZ}-\mathrm{PM}+\mathrm{BT}-\mathrm{PM})$ deposited in feath- 
Table 1: Simple regression models $(N=17, \mathrm{df}=1,15)$ between vulture plumage color measurements (spectrophotometer and visual color scores) and contents of each melanin pigment and total sum of melanin pigment concentrations

\begin{tabular}{|c|c|c|c|c|c|c|c|c|c|}
\hline & \multicolumn{3}{|c|}{ Lightness $\left(\mathrm{L}^{*}\right)$} & \multicolumn{3}{|c|}{ Chroma $\left(a^{*}\right)$} & \multicolumn{3}{|c|}{ Color score } \\
\hline & $r$ & $F$ & $P$ & $r$ & $F$ & $P$ & $r$ & $F$ & $P$ \\
\hline EM & -.87 & 49.0 & $<.001$ & -.86 & 40.8 & $<.001$ & -.74 & 18.4 & $<.001$ \\
\hline BZ-PM & -.77 & 22.5 & $<.001$ & -.64 & 10.6 & .005 & -.72 & 15.9 & .001 \\
\hline BT-PM & .36 & 2.1 & .166 & .42 & 3.2 & .097 & .25 & 1.0 & .326 \\
\hline Total & -.77 & 21.8 & $<.001$ & -.69 & 13.4 & .002 & -.69 & 13.0 & .002 \\
\hline
\end{tabular}

Note: EM, eumelanin; BZ-PM, benzothiazine pheomelanin; BT-PM, benzothiazol pheomelanin; total, EM + BZ-PM + BT-PM.

ers during growth (table 1; fig. 2). Residuals of all models showed normal distributions (K-S test, $d<0.1, P>.20$ ).

Total melanin was significantly and positively correlated with the sum of the concentrations of melanin pigments $\left(\mathrm{EM}+\mathrm{BZ}-\mathrm{PM}+\mathrm{BT}-\mathrm{PM} ; r_{s}=0.87, P<.001, n=17\right)$, indicating that the color of the homogenate $(500-\mathrm{nm}$ absorbance) effectively reflects total melanin concentration. Feather lightness was significantly and negatively correlated with total melanin $\left(r_{s}=-0.87, P<.001, n=17\right)$ and the ratio of TTCA/4-AHP markers $\left(r_{s}=-0.80, P<.001, n=\right.$ $17)$; it was significantly and positively correlated with the ratio of TTCA/PTCA markers $\left(r_{s}=0.69, P=.002, n=\right.$ 17). That is, paler feathers had lower total melanin and lower TTCA/4-AHP but higher TTCA/PTCA ratios (fig. A2).

\section{Sexual Differences and Sunlight Exposure}

Neither nest quality nor laying date was significantly explained by sunlight exposure (GLM, both $P>.45$ ). The relationship between plumage color and nest orientation was not statistically significant ( $P=.125$; fig. A3). The best model obtained for vulture color included sex and sunlight exposure as explanatory variables (table $\mathrm{A} 1$; tables $\mathrm{A} 1-\mathrm{A} 3$ are available online). Fledgling females showed a paler brown appearance than males (table 2; fig. 3), as did fledglings from nests more exposed to sunlight (table 2; fig. 4). Differences among nests showed significant variation (covariance parameters: estimate $=0.168 \pm 0.08$, Wald test $Z=2.15$, $P=.016)$. Residuals of the model showed a normal distribution (K-S test, $d=0.99, P=.417$ ). Fledgling sex was not significantly correlated with sunlight exposure (generalized linear mixed model [GLMM], $P=.696$ ).

The higher color score of 14 (25\%) individuals in September made the difference between the first and second color scoring statistically significant (paired $t$-test $=4.29, P<$ $.001, n=55$; July mean $=2.8 \pm 1.1$, September mean $=$ $3.0 \pm 1.0$ ). The time elapsed between the first and the second visual scoring was $78.5 \pm 5.9$ days on average (range $=$ 68-85 days). Color difference was positively correlated with the time elapsed between the two measurements and marginally significant with sunlight exposure (table A2). The in-
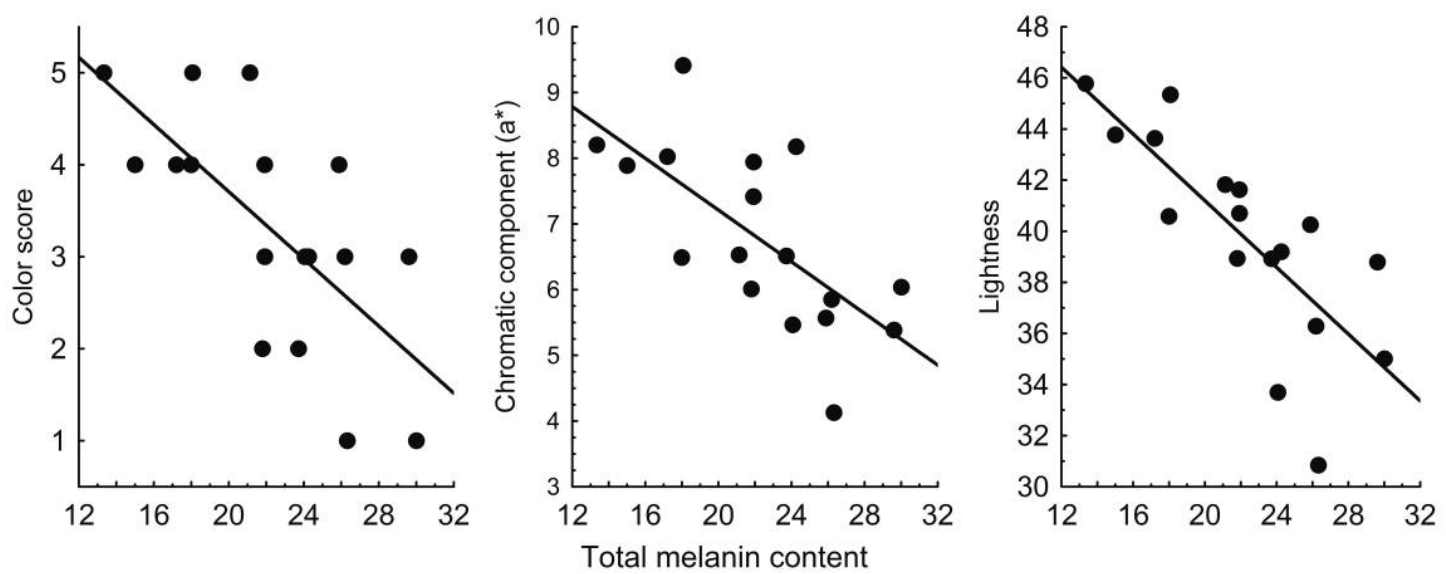

Figure 2: Relationship between plumage color measurements (visual and spectrophotometer) and the sum of the concentrations of melanin pigments $(\mathrm{EM}+\mathrm{BZ}-\mathrm{PM}+\mathrm{BT}-\mathrm{PM})$ in fledgling vulture feathers. 
Table 2: First top-ranked linear mixed model showing relationship between fledgling plumage coloration of vultures and nest sunlight exposure.

\begin{tabular}{lccccccc}
\hline & Mean \pm SD & Estimate & SE & df & $F$ & $95 \%$ CI & $P$ \\
\hline $\begin{array}{l}\text { Sex: } \\
\quad \text { Females }\end{array}$ & $3.0 \pm 1.1$ & -.320 & .1 & 1,47 & 7.4 & -.56 to -.08 & .009 \\
$\quad \begin{array}{l}\text { Males } \\
\text { Exposure }\end{array}$ & $2.6 \pm 1.1$ & & & & & & \\
\hline
\end{tabular}

Note: Sex differences are also shown. CI, confidence interval.

teraction of both variables was also statistically significant (table A2).

\section{Fitness and Plumage Coloration}

The parametric bootstrap goodness of fit test indicated that the global CMR model (model 16 in table 3) met the assumptions of independence and no heterogeneity $(P=.101)$. After correcting for overdispersion $(\hat{c}=1.407)$, we obtained four top-ranked models within 2 QAICc points that had the same resighting structure (see models 1-4 in table 3 ). The probability of reencountering griffon vultures depended on sex, age (two age classes, first-year and older birds), and cohort for birds $>1$ year of age. These models indicated a marked effect of age on survival, with lower survival in first-year individuals than in older birds. This effect seems to be especially important in males, but two of the four topranked models (models 2 and 4 in table 3 ) did not incorporate sex-biased survival. We assessed the effect of fledgling plumage coloration on survival by incorporating this covariate in the four top-ranked models (models 1-4 in table 3). According to QAICc weights, CMR models incorporating plumage coloration were 11 times more supported than models without this effect (table 4). Model averaging suggested that plumage coloration influenced survival mostly during the first year of life, with a marked difference between sexes (fig. 5). Paler males showed lower survival prospects during their first year than darker ones (average $\phi \pm$ SE: birds scored 1, $0.86 \pm$

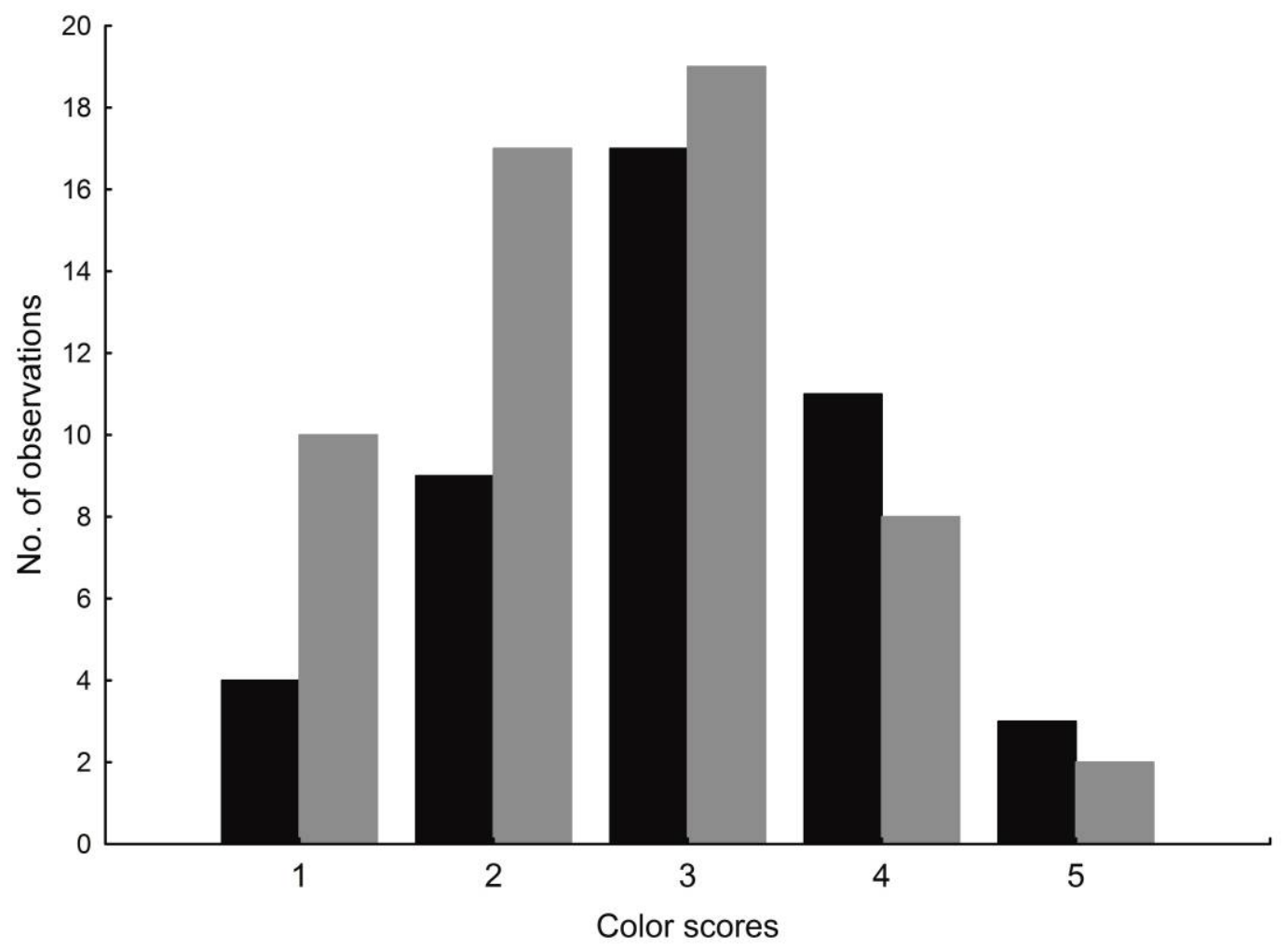

Figure 3: Plumage color score distribution of male (gray bars) and female (black bars) vultures. 


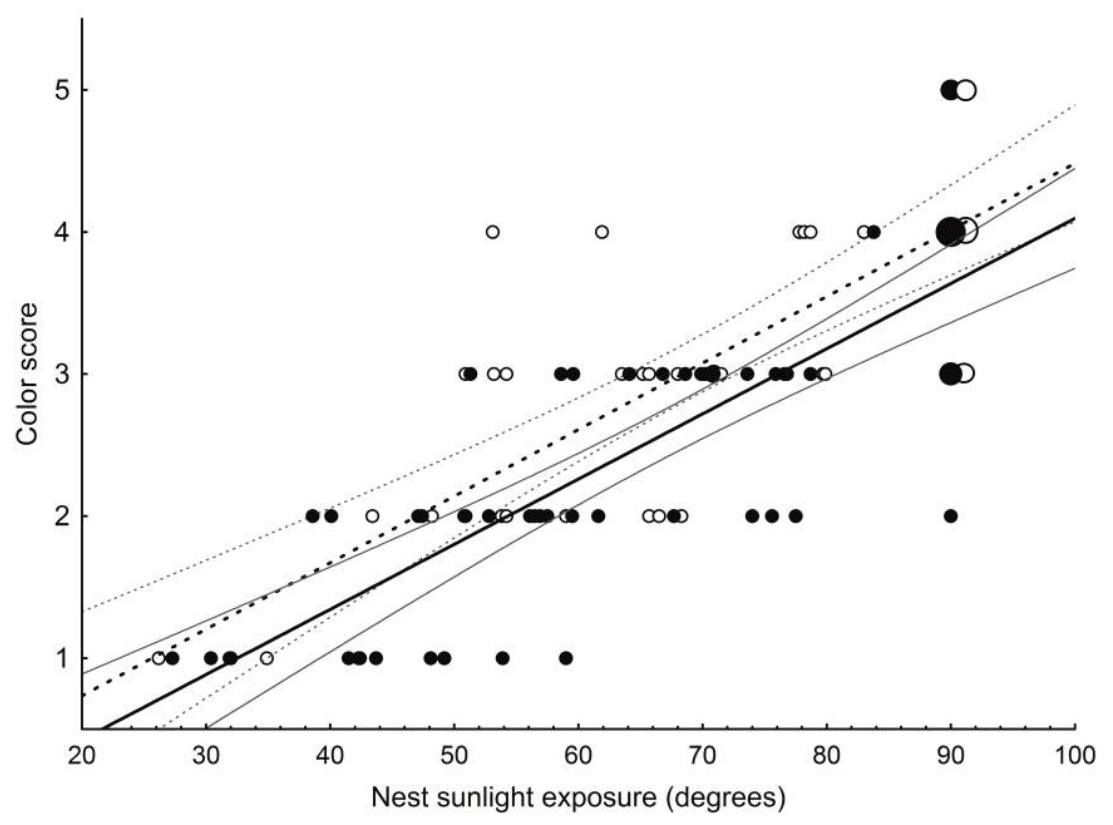

Figure 4: Relationship ( $\pm 95 \%$ confidence interval) between fledgling plumage coloration and exposure to sunlight at the nest in griffon vultures. Open circles and dashed lines represent females, and filled circles and solid lines represent males. Circles of increasing size represent $1,2,4,5$, and 7 overlapping data points.

0.12 ; birds scored 5, $0.39 \pm 0.25$; fig. 5). In contrast, paler females seemed to survive slightly better during their first year of life than darker ones (average $\phi \pm$ SE: birds scored 1 , $0.81 \pm 0.16$; birds scored 5, $0.92 \pm 0.09$; fig. 5), although this trend was much less evident. At older ages, the pattern was similar but far less marked than in first-year birds.

No clear model differences (AICc $>2$ ) were obtained for 16-year offspring production (table A3). Controlling for the

Table 3: Capture-mark-recapture models for the effect of age $(a)$, sex $(s)$, and cohort $(c)$ on survival $(\phi)$ and reencounter ( $p$ ) probabilities of griffon vultures

\begin{tabular}{|c|c|c|c|c|}
\hline Model & QAICc & $\Delta$ QAICc & wQAICc & K \\
\hline 1. $\phi([a 1, \geq a 2] \times s) p([a 1, \geq a 2] \times s)+(\geq a 2 \times c)$ & 875.78 & .00 & .27 & 14 \\
\hline 2. $\phi([a 1, a 2, \geq a 3]) p([a 1, \geq a 2] \times s)+(\geq a 2 \times c)$ & 875.90 & .12 & .26 & 13 \\
\hline 3. $\phi([a 1, a 2, \geq a 3] \times s) p([a 1, \geq a 2] \times s)+(\geq a 2 \times c)$ & 877.04 & 1.26 & .15 & 16 \\
\hline 4. $\phi([a 1, \geq a 2]) p([a 1, \geq a 2] \times s)+(\geq a 2 \times c)$ & 877.22 & 1.44 & .13 & 12 \\
\hline 5. $\phi([a 1, \geq a 2] \times s) p([a 1, \geq a 2] \times s \times c)$ & 879.05 & 3.28 & .05 & 20 \\
\hline 6. $\phi([a 1, a 2, a 3-5, \geq a 6] \times s) p([a 1, \geq a 2] \times s)+(\geq a 2 \times c)$ & 879.21 & 3.44 & .05 & 18 \\
\hline 7. $\phi([a 1, a 2-5, \geq a 6] \times s) p([a 1, \geq a 2] \times s)+(\geq a 2 \times c)$ & 879.80 & 4.03 & .04 & 16 \\
\hline 8. $\phi([a 1, a 2, a 3, \geq a 4] \times s) p([a 1, \geq a 2] \times s)+(\geq a 2 \times c)$ & 880.87 & 5.10 & .02 & 18 \\
\hline 9. $\phi(s) p([a 1, \geq a 2] \times s)+(\geq a 2 \times c)$ & 882.82 & 7.04 & .01 & 12 \\
\hline 10. $\phi([a 1, \geq a 2] \times s) p([a 1, a 2-5, \geq a 6] \times s \times c)$ & 882.93 & 7.16 & .01 & 28 \\
\hline 11. $\phi([a 1, a 2, a 3-5, \geq a 6] \times s \times c) p([a 1, \geq a 2] \times s)+(\geq a 2 \times c)$ & 884.59 & 8.81 & .00 & 31 \\
\hline 12. $\phi() p.([a 1, \geq a 2] \times s)+(\geq a 2 \times c)$ & 885.25 & 9.47 & .00 & 11 \\
\hline 13. $\phi(s) p([a 1, \geq a 2] \times s \times c)$ & 886.88 & 11.10 & .00 & 18 \\
\hline 14. $\phi() p.([a 1, \geq a 2] \times s \times c)$ & 887.09 & 11.32 & .00 & 16 \\
\hline 15. $\phi() p.([a 1, \geq a 2] \times s)+(\geq a 2 \times c)$ & 887.34 & 11.56 & .00 & 12 \\
\hline 16. $\phi([a 1, a 2, a 3-5, \geq a 6] \times s \times c) p([a 1, a 2, a 3-5, \geq a 6] \times s \times c)$ & 907.33 & 31.55 & .00 & 52 \\
\hline 17. $\phi() p.()$. & 961.87 & 86.10 & .00 & 2 \\
\hline
\end{tabular}

Note: Age classes are denoted as $a 1, a 2, a 3-5$, and $a 6$ for birds ages $1,2,3-5$, and $>5$ years, respectively. Models are ranked according to their quasi-AICc (QAICc) and Akaike weights (wQAICc). The relative change in QAICc score ( $\triangle$ QAICc) and the number of parameters $(K)$ of each model are also shown. Only the 15 top-ranked models are shown. The general (model 16) and constant (model 17) models are also shown. 
Table 4: Models used to assess variations in griffon vulture survival as a function of fledgling plumage coloration

\begin{tabular}{|c|c|c|c|c|}
\hline Model & QAICc & $\Delta$ QAICc & wQAICc & $K$ \\
\hline 1. $([a 1, \geq a 2] \times s)+(a 1 \times \mathrm{col})$ & 871.46 & .00 & .24 & 15 \\
\hline 2. $([a 1, \geq a 2] \times s)+(a 1 \times \operatorname{col} \times s)$ & 872.87 & 1.41 & .12 & 17 \\
\hline 3. $([a 1, a 2, \geq a 3] \times s)+(\text { col:males })^{1}$ & 872.93 & 1.46 & .12 & 17 \\
\hline 4. $([a 1, \geq a 2] \times s)+(a 1 \times \mathrm{col} \times s)^{1}$ & 873.37 & 1.90 & .09 & 16 \\
\hline 5. $([a 1, \geq a 2] \times s)+(\mathrm{s} \times \mathrm{col})$ & 873.51 & 2.05 & .09 & 16 \\
\hline 6. $([a 1, \geq a 2] \times s)+(\text { col:a1 males })^{1}$ & 874.18 & 2.71 & .06 & 15 \\
\hline 7. $([a 1, \geq a 2] \times s \times \mathrm{col})$ & 874.33 & 2.86 & .06 & 18 \\
\hline 8. $([a 1, a 2, \geq a 3] \times s)+(s \times \mathrm{col})$ & 874.98 & 3.52 & .04 & 18 \\
\hline 9. $([a 1, a 2, \geq a 3] \times s)+(a 1 \times s \times \mathrm{col})$ & 875.57 & 4.11 & .03 & 19 \\
\hline 10. $([a 1, \geq a 2] \times s)$ & 875.78 & 4.31 & .03 & 14 \\
\hline 11. $([a 1, a 2, \geq a 3])$ & 875.90 & 4.43 & .03 & 13 \\
\hline 12. $([a 1, \geq a 2, a 3] \times s)$ & 877.04 & 5.57 & .01 & 16 \\
\hline 13. $([a 1, \geq a 2])$ & 877.22 & 5.76 & .01 & 12 \\
\hline 14. $([a 1, \geq a 2] \times s)+([a 1 \times \mathrm{col}]+s)$ & 877.26 & 5.79 & .01 & 16 \\
\hline 15. $([a 1, \geq a 2] \times s)+(\operatorname{col}: a 1)^{1}$ & 877.62 & 6.15 & .01 & 15 \\
\hline
\end{tabular}

Note: Plumage coloration (col) was added as an individual covariate to the best models obtained in a previous modeling stage (see models 1-4 in table 3 ) in which survival and reencounter probabilities were modeled as functions of age, sex, and cohort. Age (a) is the number of age classes considered (e.g., $[a 1, \geq a 2]$ includes one parameter for first-year birds and another for older birds), $s$ is sex, plus sign denotes additive effects, times symbol denotes interaction terms, and colon denotes covariate effects in only one age-sex class. Common intercept parameterizations are specified with superscript 1. Models are ranked according to their quasi-AICc (QAICc) and Akaike weights (wQAICc). The relative change in QAICc score $(\triangle \mathrm{QAICc})$ and the number of parameters $(K)$ in each model are also shown. The model structure for recapture probabilities was kept as the best model from table 3 . Only the 15 top-ranked models are shown.

variation explained by laying date and between-year differences, GLMM showed that both plumage color and sex were terms retained in the 15 top-ranked models contributing to explain 16-year offspring production. Overall, paler individuals produced fewer offspring during this period (fig. A4).

\section{Discussion}

\section{Sunlight Exposure, Color Variation, and Melanin Content}

Vulture nestlings grown in nests more exposed to sunlight developed paler plumage than those from more sheltered nesting sites. Variations in the lightness and chromatic components of plumage were associated with the deposition of melanin in the plumage, with paler feathers having lower concentrations of different melanin pigments (EM and BZ-PM), lower sums of melanin pigment concentrations (EM + BZ-PM + BT-PM), and lower total melanin $(\mathrm{A} 500 \mathrm{~nm})$ in the homogenates.

In a physical bleaching scenario, melanin concentration should not be correlated with lightness because feather changes resulting in lightening are independent of pigment concentration. Similarly, in a pigmentary (chemical) bleaching process, an increase in the concentration of the TTCA marker (BZ-PM) with feather lightness due to 4-AHP (BT-PM) photodegradation would be expected, thus promoting a negative correlation between BZ-PM and BT-PM (Wakamatsu et al. 2012). Instead, our results showed that BZ-PM decreases with feather lightness, indicating a lack of BT-PM degrada- tion and signifying a lower deposition of the pigment in paler feathers. Furthermore, no significant correlation was found between BZ-PM and BT-PM. Because our results showed that total melanin varied with feather lightness, the ratios TTCA/ 4-AHP and TTCA/PTCA are no longer informative. The lower deposition of BZ-PM in paler feathers explains the negative correlation with the TTCA/4-AHP ratio. On the other hand, the positive correlation found between TTCA/PTCA and feather lightness indicates that more BZ-PM (the palest pigment) relative to EM (the darkest pigment) is deposited in paler feathers. These results do not support the idea that feather lightening is due to structural changes or pigment degradation. However, mean visual color estimations made in September were significantly higher than those made in July because of the increase in color rank in $25 \%$ of individuals. This color change tended to occur when the elapsed time (number of days) was longer and when individuals were more exposed to sunlight, suggesting that some bleaching took place from the first to second color estimation in welldeveloped fledgling feathers. Nevertheless, the interaction between sunlight exposure and time elapsed from July to September was not observed to affect plumage color variation of fledglings in the nest. The time elapsed from birth (hatching) to the age of the fledglings in the month of July when the first visual color measurement was taken varied from 82 to 137 days. Neither time variation nor the interaction between time and sunlight exposure affected the variation of fledgling plumage coloration. Therefore, our results do not support the idea that bleaching is a mechanism underlying plumage color 


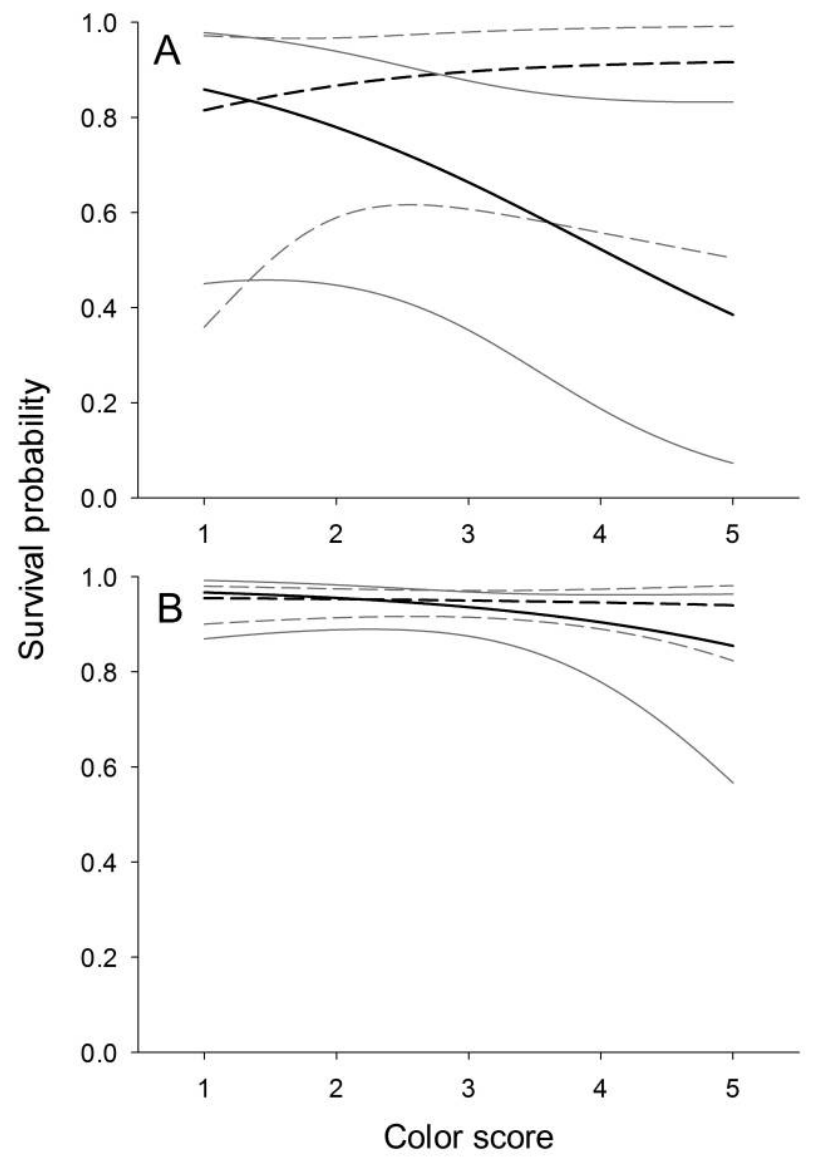

Figure 5: Estimates ( $\pm 95 \%$ confidence interval) of survival of firstyear $(A)$ and older $(B)$ griffon vultures in relation to their plumage coloration as fledglings. Estimates of survival were obtained by averaging models of table 4 . Solid and dashed lines represent males and females, respectively.

variation in vulture fledglings in the nest, but they do support melanin deposition as a factor in feather color variation.

Nests more exposed to sunlight produced similar number of fledglings as less exposed ones over a period of 20 years. In addition, no significant correlation was found between nest sunlight exposure and laying date. Taken together, these results indicate that sunlight exposure does not influence nest quality. Alternatively, variation in coloration may reflect varying strategies of individuals for different local conditions of solar radiation or temperature (Sirkia et al. 2010; Karell et al. 2011). For instance, individuals might choose nesting sites on the basis of sunlight exposure to optimize breeding success, such that paler individuals nest in more exposed nests while darker individuals nest in less exposed ones. However, our results showed that paler fledgling males grown in more exposed nests had lower viability. Furthermore, offspring sex ratio was not correlated with sunlight exposure of the nest, suggesting that parental nesting site choice (in terms of sunlight conditions) is not based on the sex of the offspring These results do not support the idea of coloration-dependent behavior adapted to sunlight temperature conditions of the nest. Nevertheless, it cannot be ignored that heterogeneous climatic conditions in space and time may promote viability selection on plumage coloration (Karell et al. 2011). Although our study does not directly support the idea of parental quality or the idea of a nesting behavior linked to the color phenotype as mechanisms explaining the variation in vulture fledgling plumage coloration, these hypotheses cannot be ruled out because more data on reproduction or even survival are required for longer periods of time.

The striking relationship between fledgling plumage coloration and sunlight exposure of the nest suggests the existence of acclimatization or phenotypic plasticity in plumage coloration as a result of variation in temperature and/or sunlight radiation at the nest during development. Paler phenotypes in warmer geographic regions (and darker ones in colder regions) have been recorded for different taxa, including birds (Zink and Remsen 1986; Gibert et al. 1998; Clusella-Trullas et al. 2008; Zeuss et al. 2014). Within natural populations and under experimental laboratory conditions, increases in temperature resulted in paler phenotypes in insects (Gibert et al. 1998), fishes (Horth 2003), salamanders (García et al. 2003), and lizards (Rosenblum 2005), indicating ontogenetic and/or physiological changes in phenotypic coloration leading to darker colors in colder environments. In birds or mammals, there are no solid studies exploring within-population variation in plumage or fur coloration in relation to climatic conditions either in the wild or in the laboratory. Beebe (1907) carried out an experiment confining several individuals of three bird species (Hylocichla mustelina, Zonotrichia albicollis, and Columbina inca) indoors for 2-3 years in humid atmosphere conditions. He recorded the resulting plumage coloration after several molts and observed an unambiguous plumage darkening compared with those birds living outdoors. Color changes in the three species varied in the same predicted manner. Furthermore, Bieber (1972) found in the common rabbit Oryctolagus cuniculus that individuals kept in a cold condition grew a darker coat apparently because of the different length reached by the guard hair with respect to the down hair layers. Results of both studies must be interpreted with caution because of the small sample size and the lack of true control groups, but interestingly, the two studies showed a change of color in feathers and fur in response to varying conditions of humidity and temperature. To our knowledge, these two studies are the only ones to suggest plasticity in individual coloration as a potential adaptation to climatic changes in endotherms, as proposed for other organisms (Gibert et al. 1998).

The nestling stage of griffon vultures lasts about 120 days until fledging, including the warmest months of the year in 
the study area (June, July, and August). In the Mediterranean region, nestlings generally cannot protect themselves from direct solar radiation and heat, particularly in nests located on open ledges without cover. Thus, parents shade them during the first weeks after hatching to prevent nestling overheating (Xirouchakis and Mylonas 2007; J. A. Fargallo, F. Martínez, and G. Blanco, personal observation). The mere existence of this parental behavior indicates the need for mechanisms to reduce heating. Pale body coloration in vultures may be one of the mechanisms evolved as a response to high sunlight exposure, thus supporting the thermal melanism hypothesis, which predicts a paler coloration in the warmest regions. Conversely, our results contradict the hypothesis predicting an enhanced protection against UV radiation by dark phenotypes, probably because feathers have sufficient protective capacity against UV radiation regardless of their color (Porter 1967).

The physiological mechanisms allowing change in plumage coloration as a potential response to sunlight temperature variations are unknown. Rapid body color changes observed in fishes, amphibians, and reptiles in response to varying conditions of temperature and radiation are due to the rapid expansion (darkening) and retraction (lightening) of pigment organelles (melanosomes) in the pigment cells (melanophores) of the dermis, which is both neurohumorally and hormonally regulated (Filadelfi and Castrucci 1996; Tuma et al. 1998; Sköld et al. 2013). Color works differently in feathers and fur. Color changes in these keratinized structures are slow, mainly ontogenetic, and depend on the pigment transfer from dermal melanocytes to the keratinocytes during the formation of feathers and fur. It is known that melanogenesis is sensitive to hormone and hormone-stress variations that can affect first the pigmentation of melanocytes in follicles and then the final color in the growing fur (reviewed in Tobin and Kauser 2005). It is also known that bird physiology can be affected by ambient temperature during growth (Siegel 1980; Lin et al. 2006; Salaberría et al.2014) and that experimental and natural variations of temperature can result in modifications of plasma corticosterone and testosterone concentrations (Edens and Siegel 1975; Wingfield et al. 1982; Dorn et al. 2014), with these two hormones having a visible effect on melanin-based plumage coloration during growth (Fargallo et al. 2007b, Roulin et al. 2010). This (or another unknown mechanism) may be behind the plumage color trait plasticity of growing vultures in response to temperature/sunlight by potentially controlling melanin deposition in feathers.

On the other hand, the observed variation in plumage coloration may just reflect the physiological health status of the fledglings. Poultry science studies have reported that birds (mainly chickens Gallus gallus domesticus) under elevated temperature conditions undergo significant physiological and metabolic changes to accomplish homeostasis, and acute heat stress situations can even lead to physiological dysfunctions that consequently affect survival (Siegel 1980; Lin et al. 2006). Among the physiological effects provoked by heat stress are food intake reduction, increased enzymatic activity, increased plasma corticosterone levels, immunosuppression, increased susceptibility to infectious diseases, intestinal injury, and induction of oxidative stress or lipid peroxidation (Siegel 1980; Bogin et al. 1997; Garriga et al. 2006; Lin et al. 2006; Quinteiro-Filho et al. 2010). Thus, it cannot be ruled out that the more exposed nestling vultures in the colony may suffer from heat stress, with melanogenesis or melanin deposition being costly functions competing with other priority functions for the restoration of homeostasis, thus promoting plumage lightening. The observed color variation in fledgling vulture plumage can be accounted for by (1) temporary facultative (acclimatization) or permanent (phenotypic plasticity) changes as adaptive mechanisms set to fit environmental conditions; (2) the direct action of environmental factors on vulture physiology, with plumage coloration reflecting health status; or (3) a mix of both, with plumage color variation in response to sunlight temperature conditions possibly entailing physiological costs when close to temperatures that generate thermally stressful situations (Wilson and Franklin 2002). Of interest for the effect of sex in our study is that males seem to be more stressed than females under acute heat conditions during development, suffering from greater physiological changes that ultimately reduce survival (Edens and Siegel 1975; Bogin et al. 1997; Lin et al. 2006).

\section{Coloration-Related Survival and Sexual Dimorphism}

The CMR models indicate that females tended to survive better than males and that survival was lower during the first year of life in vultures. The model also showed that the interaction between sex and plumage coloration contributes to explain vulture survival. While no clear relationship between color and survival was observed for females, paler male individuals showed lower survival probability and higher mortality during the first year of life. It was also observed that offspring productivity in the first 16 years of life was lower for the vultures that were paler at fledging time. This result can be explained as a consequence of the low productivity resulting from high mortality in the paler males. The results obtained from productivity must be interpreted with caution: although collecting data for 16 years is a great effort, this period of time is not enough to evaluate lifetime reproductive success in long-lived species, such as the griffon vulture (Chantepie et al. 2016).

Our study does not provide information on the causes behind the correlation between plumage coloration and fitness components or the reason why this correlation differs between sexes. It has become increasingly clear that phenotypes are a set of traits with different patterns of genetic, functional, or developmental integration through multicovariation or 
multicorrelation (Pigliucci and Preston 2004). Particularly, it has been reported that melanic plumage coloration can mirror other life-history traits - such as body condition, immunocompetence, parasite infection, testis size, endocrine profiles, or aggressive behavior (Evans et al. 2000; Fargallo et al. 2007a, 2014; Bókony et al. 2008; Gasparini et al. 2009; Blanco and Fargallo 2013) - that can affect fitness (Brommer et al. 2005; Roulin et al. 2010; Kim et al. 2013) and promote multivariate responses to selection (Kim et al. 2013). In addition, the ways in which other phenotypic traits integrate genetically or phenotypically with plumage coloration can differ between sexes (Kim et al. 2013; Fargallo et al. 2014; LópezRull et al. 2016), indicating sexual differences in fitnessrelated optima for the covariation between plumage coloration and other life-history traits (Kim et al. 2013; López-Rull et al. 2016). The within- and between-sex variation in plumage coloration found in vultures may be the result of selection pressures on the trait itself or due to selection on other traits that covary with melanin-based coloration.

On the other hand, the acclimatization of traits to fit environmental conditions may entail costs (DeWitt et al. 1998; Beaman et al. 2016). These acclimatization costs have been proposed to be the cause of fitness reduction associated with increasing resistance to high temperatures (e.g., Hoffmann and Hewa-Kapuge 2000; Wilson and Franklin 2002). Accordingly, if color variation in the plumage of vulture fledglings in relation to sunlight exposure reflects acclimatization capacity (norms of reaction in the case of phenotypic plasticity), paler phenotypes might reflect high solar radiation temperature conditions during growth, with the palest phenotypes indicating growth conditions with some degree of physiological heat stress, thus inducing fitness costs. Therefore, a nonexclusive explanation for our results is that biased mortality toward paler males might indicate a sex-related acclimatization cost of increasing resistance to stressful temperatures induced by solar radiation. This is supported by the fact that males have been shown to be more vulnerable than females to acute heat stress episodes during growth (Edens and Siegel 1975; Siegel 1980; Bogin et al. 1997; Lin et al. 2006).

Our results reveal a sexual difference in fitness-related optima for fledgling plumage coloration, potentially indicating sexually antagonistic selection through a male-biased mortality of paler phenotypes. It has recently been proposed that developmental conditions can change mean trait values and modify the capacity for acclimation by considering this capacity as a quantitative trait that can be modulated by developmental processes (Beaman et al. 2016). The lower survival of individuals exhibiting phenotypes in one extreme of the phenotypic range (palest plumages) might deplete the acclimatization capacity of males if this capacity can be inherited as in other quantitative traits. This would coincide with the weak but significant (and as yet not reported) sexual dichromatism in the juvenile plumage of the griffon vulture, in which females are paler than males. Trait divergence might be favored throughout survival, suggesting ecological causation for subtle sexual dimorphism (Temeles et al. 2000).

Another possible explanation for the significant betweensex difference found in fledgling plumage coloration could be mortality of paler males in the nest occurring before the time of the first color measurement. This should be specifically tested in future studies by increasing sample size to assess expected frequencies for each color score and by sexing chicks at hatching to determine whether there is a male-biased mortality in nests more exposed to sunlight. Regardless, the explanation proposed above is plausible as the consequence of the between-sex difference is the same, that is, greater elimination of the palest phenotypes in males because of their lower survival probability.

\section{Conclusions}

Our study indicates a close relationship between melaninbased plumage coloration and nest sunlight exposure in griffon vulture fledglings. Several ideas may underlie this relationship. In particular, no relationship was found between nest exposure and parental features, but it is necessary to consider more individual traits that could not be measured in this study, such as the condition or health status of the parents. In addition, color phenotypes may have different strategies of nesting as color behavior adaptations to heterogeneous climatic conditions. More data and for a longer period are necessary to accurately test these two ideas. Furthermore, this study shows that already grown vulture feathers can be lightened during the fledging period (from July to September). However, time had no effect on plumage variation observed during the nesting period as coloration was not related with the chick age at which the first color measurement was taken. Coloration was also not related with melanin pigment and markers in the way predicted by bleaching. Therefore, even if some bleaching occurred, that process only partially explained a negligible proportion of the plumage color variation of fledglings after leaving the nest. Acclimatization serves as a plausible explanation for the color variation in plumages, and its direction (lightening coloration in response to solar radiation) is consistent with the thermal melanism hypothesis. The acclimatization potential of birds through plumage coloration has not been investigated since the pioneering work of Beebe (1907). Our results suggest a potential capacity of birds to respond to local solar radiation temperature conditions by changing feather coloration through varying melanin deposition in growing feathers. The potential acclimatization capacity of endotherms through the modification of external phenotypic traits, such as coloration, might affect the physiological thermal tolerance of species and therefore the biogeographic predictions in relation to the ambient climatic variability. In addition, the plumage coloration ob- 
tained at the nestling stage predicts sex-biased fitness. The interaction found in the survival probability between sex and plumage coloration suggests that acclimatization capacity as a strategy to adapt to local conditions may be favored in females, because no clear trend was observed in survivalrelated coloration in this sex compared with males in which paler individuals clearly suffered higher mortality. Males seem to be more vulnerable to sunnier, warmer environments, as also reported in poultry science studies. The greater elimination of paler phenotypes might deplete the acclimatization capacity of males in sunnier, warmer conditions and shift the optimum expression of plumage coloration toward darker individuals, thus generating sexual divergence in homologous traits and inducing sexual dimorphism. Further investigation is required to determine (1) the physiological changes and health status associated with plumage coloration under heat stress conditions and (2) the interaction, if any, between acclimatization and phenotypic plasticity processes.

\section{Acknowledgments}

We thank O. Frías, J. L. González, and J. M. García for their help with fieldwork and D. López-Idiáquez for helping with statistical procedures. The study was carried out with the permission of the regional government of Castilla y León, Dirección General del Medio Natural, Servicio de Espacios Naturales. Research was funded by the Spanish Ministry of Economy, Industry, and Competitiveness through projects CGL2007-61395, CGL2010-15726, and CGL2013-42451-P.

\section{Literature Cited}

Angilletta, M. J., Jr., B. S. Cooper, M. S. Schuler, and J. G. Boyles. 2010. The evolution of thermal physiology in endotherms. Frontiers in Bioscience 2:861-881.

Angilletta, M. J., Jr., M. W. Sears, and R. M. Pringle. 2009. Spatial dynamics of nesting behavior: lizards shift microhabitats to construct nests with beneficial thermal properties. Ecology 90:2933-2939.

Auld, J. R., A. A. Agrawal, and R. A. Relyea. 2010. Re-evaluating the costs and limits of adaptive phenotypic plasticity. Proceedings of the Roval Societv B 277:503-511.

Bagnara, J. T., J. Matsumoto, W. Ferris, S. K. Frost, W. A. Turner Jr., T. T. Tchen, and J. D. Taylor. 1979. Common origin of pigment cells. Science 203:410-415.

Barton, K. 2016. MuMIn: multi-model inference. R package version 1. 15.6.

Bates, D., M. Mächler, B. Bolker, and S. Walker. 2015. Fitting linear mixed-effects models using lme4. Iournal of Statistical Software 67:1-48.

Bateson, P., D. Barker, T. Clutton-Brock, D. Deb, B. D’Udine, R. A. Foley, P. Gluckman, et al. 2004. Developmental plasticity and human health. Nature 430:419-421.

Beaman, J. E., C. R. White, and F. Seebacher. 2016. Evolution of plasticity: mechanistic link between development and reversible acclimation. Trends in Ecology and Evolution 31:237-249.
Beebe, W. 1907. Geographic variation in birds, with especial reference to the effects of humidity. Zoologia 1:3-41.

Berggren, A., D. P. Armstrong, and R. M. Lewis. 2004. Delayed plumage maturation increases overwinter survival in North Island robins. Proceedings of the Roval Societv B 271:2123-2130.

Bergman, G. 1982. Why are the wings of Larus f. fuscus so dark? Ornis Fennica 59:77-83.

Bieber, H. 1972. Fellverdunklung beim hauskaninchen nach kälteeinwirkung. Zeitschrift für Säugetierkunde 38:33-38.

Blanco, G. 2014. Can livestock carrion availability influence diet of wintering red kites? implications of sanitary policies in ecosystem services and conservation. Population Ecology 56:593-604.

Blanco, G., and J. A. Fargallo. 2013. Wing whiteness as an indicator of age, immunocompetence and testes size in the European magpie. Auk 130:399-407.

Blanco, G., O. Frías, J. Garrido-Fernández, and D. Hornero-Méndez. 2005. Environmental-induced acquisition of nuptial plumage expression: a role of denaturation of feather carotenoproteins? Proceedings of the Roval Society B 272:1893-1900.

Blanco, G., and F. Martínez. 1996. Sex differences in breeding age of griffon vultures Gyps fulvus. Auk 113:247-248.

Blanco, G., F. Martínez, and J. M. Traverso. 1997. Pair bond and age distribution of breeding griffon vultures Gyps fulvus in relation to reproductive status and geographic area in Spain. Ibis 139:180-183.

Bogin, E., H. C. Peh, Y. Avidar, B. Israeli, E. Kevkhaye, P. Lombardi, and A. Cahaner. 1997. Sex and genotype dependence on the effects of long term high environmental temperatures on cellular enzyme activities from chicken organs. Avian Pathology 26:511-524.

Bókony, V., L. Z. Garamszegi, K. Hirschenhauser, and A. Liker. 2008. Testosterone and melanin-based black plumage coloration: a comparative study. Behavioural Ecology and Sociobiology 62:1229-1238.

Bonduriansky, R., and S. F. Chenoweth. 2009. Intralocus sexual conflict. Trends in Ecology and Evolution 24:280-288.

Boonstra, R. 2013. Reality as the leading cause of stress: rethinking the impact of chronic stress in nature. Functional Ecology 27:11-23.

Boyles, J. G., F. Seebacher, B. Smit, and A. E. McKechnie. 2011. Adaptive thermoregulation in endotherms may alter responses to climate change. Integrative and Comparative Biology 51:676-690.

Bradbury, J. W., and S. L. Vehrencamp. 2011. Principles of animal communication. 2nd ed. Sinauer, Sunderland, MA.

Brommer, J. E., K. Ahola, and T. Karstinen. 2005. The colour of fitness: plumage coloration and lifetime reproductive success in the tawny owl. Proceedings of the Roval Society B 272:935-940.

Burnham, K. P., and D. R. Anderson. 2002. Model selection and multimodel inference: a practical information-theoretic approach. Springer, New York.

Burtt, E. H., Jr. 1986. An analysis of physical, physiological and optical aspects of avian coloration with emphasis on wood-warblers. American Ornithologist's Union, Washington, DC.

Burtt, E. H., Jr., and J. M. Ichida. 2004. Gloger's rule, feather-degrading bacteria, and color variation among song sparrows. Condor 106:681686.

Cade, B. S. 2015. Model averaging and muddled multimodel inferences. Ecology 96:2370-2382.

Cano, J. 1990. Estudio climatológico del refugio de rapaces de Montejo (Segovia). Revista de Meteorología 13:81-91.

Caro, T. 2005. The adaptive significance of coloration in mammals. BioScience 55:125-36.

Carranza, J. 2004. Sex allocation within broods: the intrabrood sharingout hypothesis. Behavioral Ecology 15:223-232. 
Chantepie, S., C. Teplitsky, S. Pavard, F. Sarrazin, B. Descaves, P. Lecuyer, and A. Robert. 2016. Age-related variation and temporal patterns in the survival of a long-lived scavenger. Oikos 125:167-178.

Chenoweth, S. F., H. D. Rundle, and M. W. Blows. 2008. Genetic constraints and the evolution of display trait sexual dimorphism by natural and sexual selection. American Naturalist 171:22-34.

Clusella-Trullas, S., J. S. Terblanche, T. M. Blackburn, and S. L. Chown. 2008. Testing the thermal melanism hypothesis: a macrophysiological approach. Functional Ecology 22:232-238.

Cooch, E., and G. C. White. 2016. Program MARK: a gentle introduction. 16th ed. Colorado State University, Fort Collins. http://www.cnr .colostate.edu/ gwhite/mark/mark.htm.

Cox, R. M., and R. Calsbeek. 2009. Sexually antagonistic selection, sexual dimorphism, and the resolution of intralocus sexual conflict. American Naturalist 173:176-187.

DeWitt, T. J., A. Sih, and D. S. Wilson. 1998. Costs and limits of phenotypic plasticity. Trends in Ecology and Evolution 13:1-8.

d'Ischia, M., K. Wakamatsu, A. Napolitano, S. Briganti, J. C. GarcíaBorrón, D. Kovacs, P. Meredith, et al. 2013. Melanins and melanogenesis: methods, standards, protocols. Pigment Cell and Melanoma Research 26:616-633.

Donázar, J. A. 1993. Los Buitres lbéricos: biología y conservación. JM Reyero, Madrid.

Dorn, S., C. A. F. Waschera, E. Möstl, and K. Kotrschal. 2014. Ambient temperature and air pressure modulate hormones and behaviour in greylag geese (Anser anser) and northern bald ibis (Geronticus eremita). Behavioural Processes 108:27-35.

Edens, F. W., and H. Siegel. 1975. Adrenal responses in high and low ACTH response lines of chickens during acute heat stress. General Comparative Endocrinology 25:64-73.

Elosegui, I. 1989. Vautour fauve (Gyps fulvus), Gypaete barbu (Gypaetus barbatus), Percnoptère d'Egypte (Neophron percnopterus): synthèse bibliographique et recherches. Série document de travail. Acta Biologica Montana 3.

Evans, M., A. R. Goldsmith, and S. R. A. Norris. 2000. The effects of testosterone on antibody production and plumage coloration in male house sparrows (Passer domesticus). Behavioural Ecology and Sociobiology 47:156-163.

Fargallo, J. A., T. Laaksonen, E. Korpimäki, and K. Wakamatsu. 2007a. A melanin-based trait reflects environmental growth conditions of nestling male Eurasian kestrels. Evolutionary Ecology 21:157-171.

Fargallo, J. A., F. Martínez, K. Wakamatsu, D. Serrano, and G. Blanco. 2018. Data from: Sex-dependent expression and fitness consequences of sunlight-derived color phenotypes. American Naturalist, Dryad Digital Repository, https://doi.org/10.5061/dryad.nr2m3.

Fargallo, J. A., J. Martínez-Padilla, A. Toledano-Díaz, J. SantiagoMoreno, and J. A. Dávila. 2007b. Sex and testosterone effects on growth, immunity and melanin coloration of nestling Eurasian kestrels. Lournal of Animal Ecology 76:201-209.

Fargallo, J. A., A. Velando, I. López-Rull, N. Gañán, N. Lifshitz, K. Wakamatsu, and R. Torres. 2014. Sex-specific phenotypic integration: endocrine profiles, coloration and behavior in fledgling boobies. Behavioral Ecology 25:76-87.

Filadelfi, A. M., and A. M. Castrucci. 1996. Comparative aspects of the pineal/melatonin systems of poikilothermic vertebrates. Lournal of Pineal Research 20:175-186.

Fitze, P. S., and H. Richner. 2002. Differential effects of a parasite on ornamental structures based on melanins and carotenoids. Behavioral Ecology 13:401-407.
García, T. S. R., S. R. Straus, and A. Sih. 2003. Temperature and ontogenetic effects on color change in the larval salamander species Ambystoma barbouri and Ambystoma texanum. Canadian Journal of Zoology 81:710-715.

Gasparini, J., P. Bize, R. Piault, K. Wakamatsu, J. D. Blount, A. L. Ducrest, and A. Roulin. 2009. Strength and cost of an induced immune response are associated with a heritable melanin-based colour trait in female tawny owls. Journal of Animal Ecology 78:608616.

Gibert, P., B. Moreteau, J. C. Moreteau, R. Parkash, and J. R. David 1998. Light body pigmentation in Indian Drosophila melanogaster: a likely adaptation to a hot and arid climate. Iournal of Genetics 77:13-20.

Gloger, C. L. 1833. Das abändern der vögeldurch einfluss des klima’s. Breslau, Germany.

Gómez-Mestre, I., and R. Jovani. 2013. A heuristic model on the role of plasticity in adaptive evolution: plasticity increases adaptation, population viability and genetic variation. Proceedings of the Roval Societv B 280:20131869.

Grant, G. S. 1982. Avian incubation: egg temperature, nest humidity, and behavioral thermoregulation in a hot environment. American Ornithologist's Union, Washington, DC.

Grémillet, D., L. Meslin, and A. Lescroël. 2012. Heat dissipation limit theory and the evolution of avian functional traits in a warming world. Functional Ecology 26:1001-1006.

Griffith, S. C. 2000. A trade-off between reproduction and a conditiondependent sexually selected ornament in the house sparrow Passer domesticus. Proceedings of the Roval Societv B 267:1115-1119.

Hedrick, A. V., and E. J. Temeles. 1989. The evolution of sexual dimorphism in animals: hypotheses and tests. Trends in Ecology and Evolution 4:136-138.

Hetem, R. S., B. A. de Witt, L. G. Fick, A. Fuller, G. I. H. Kerley, L. C. R. Meyer, D. Mitchell, and S. K. Maloney. 2009. Body temperature, thermoregulatory behaviour and pelt characteristics of three colour morphs of springbok (Antidorcas marsupialis). Comparative Biochemistry and Physiology A 152:379-388.

Hill, G. E., and K. J. McGraw. 2006. Bird coloration: function and evolution. Harvard University Press, Cambridge, MA.

Hochscheid, S., D. Grémillet, S. Wanless, and M. A. du Plessis. 2002. Black and white under the South African sun: are juvenile Cape gannets heat stressed? Journal of Thermal Biology 27:325-332.

Hoekstra, H. E. 2006. Genetics, development and evolution of adaptive pigmentation in vertebrates. Heredity 97:222-234.

Hoffmann, A. A., and S. Hewa-Kapuge. 2000. Acclimation for heat resistance in Trichogramma nr. brassicae: can it occur without costs? Functional Ecology 14:55-60.

Horth, L. 2003. Melanic body colour and aggressive mating behaviour are correlated traits in male mosquitofish (Gambusia holbrooki). Proceedings of the Roval Societv B 270:1033-1040.

Hubbard, J. K., B. R. Jenkins, and R. J. Safran. 2015. Quantitative genetics of plumage color: lifetime effects of early nest environment on a colorful sexual signal. Ecology and Evolution 5:3436-3449.

Hubbard, J. K., J. A. Uy, M. E. Hauber, H. E. Hoekstra, and R. J. Safran. 2010. Vertebrate pigmentation: from underlying genes to adaptive function. Trends in Genetics 26:231-239.

Ito, S., Y. Nakanishi, R. K. Valenzuela, M. H. Brilliant, L. Kolbe, and K. Wakamatsu. 2011. Usefulness of alkaline hydrogen peroxide oxidation to analyze eumelanin and pheomelanin in various tissue samples: application to chemical analysis of human hair melanins. Pigment Cell and Melanoma Research 24:605-613. 
Jackson, M. E., D. E. Scott, and R. A. Estes. 1989. Determinants of nest success in the marbled salamander (Ambystoma opacum). Canadian Lournal of Zoology 67:2277-2281.

Jones, J. C., M. R. Myerscough, S. Graham, and B. P. Oldroyd. 2004. Honey bee nest thermoregulation: diversity promotes stability. Science 305:402-404.

Jones, K. S., S. Nakagawa, and B. Sheldon. 2009. Environmental sensitivity in relation to size and sex in birds: meta-regression analysis. American Naturalist 174:122-133.

Karell, P., K. Ahola, T. Karstinen, J. Valkama, and J. E. Brommer. 2011. Climate change drives microevolution in a wild bird. Nature Communications 2:208.

Khaliq, I., C. Hof, R. Prinzinger, K. Böhning-Gaese, and M. Pfenninger. 2014. Global variation in thermal tolerances and vulnerability of endotherms to climate change. Proceedings of the Roval Society B 281:20141097.

Kim, S. Y., J. A. Fargallo, P. Vergara, and J. Martínez-Padilla. 2013. Multivariate heredity of melanin-based coloration body mass and immunity. Heredity 111:139-146.

Kovach, W. L. 2011. Oriana: circular statistics for Windows. Version 4. Kovach Computing Services, Pentraeth.

Kristensen, T. N., A. A. Hoffmann, J. Overgaard, J. G. Sørensen, R. Hallas, and V. Loeschcke. 2008. Costs and benefits of cold acclimation in field-released Drosophila. Proceedings of the National Academv of Sciences of the USA 105:216-221.

Lin, H., E. Decuypere, and J. Buyse. 2006. Acute heat stress induces oxidative stress in broiler chickens. Comparative Biochemistry and Physiology A 144:11-17.

Lindström, J. 1999. Early development and fitness in birds and mammals. Trends in Ecology and Evolution 14:343-348.

López-Rull, I., P. Vergara, J. Martínez-Padilla, and J. A. Fargallo. 2016. Early constraints in sexual dimorphism: survival benefits of feminized phenotypes. Journal of Evolutionary Biology 29:231-240.

Martínez, F., G. Blanco, and R. F. Rodríguez. 1998. Rate, timing and success of clutch replacement by colonial griffon vultures Gyps fulvus. Ornis Fennica 75:145-148.

Martínez, F., R. Rodríguez, and G. Blanco. 1997. Effects of monitoring frequency on estimates of abundance, age, distribution, and productivity of colonial griffon vultures. Journal of Field Ornithology 68: 392-399.

McGraw, K. J. 2007. Dietary mineral content influences the expression of melanin-based ornamental coloration. Behavioral Ecology 18:137-142.

McKinnon, J. S., and M. E. R. Pierotti. 2010. Colour polymorphism and correlated characters: genetic mechanisms and evolution. Molecular Ecology 19:5101-5125.

Meredith, P., and T. Sarna. 2006. The physical and chemical properties of eumelanin. Pigment Cell Research 19:572-594.

Millington, K. R., and J. S. Church. 1997. The photodegradation of wool keratin. II. Proposed mechanisms involving cystine. Journal of Photochemistry and Photobiology B 39:204-212.

Monaghan, P. 2008. Early growth conditions, phenotypic development and environmental change. Philosophical Transactions of the Roval Societv B 363:1635-1645.

Montgomerie, R. 2006. Cosmetic and adventitious colors. Pages 399430 in G. Hill and K. Mcgraw, eds. Bird coloration. Vol. 1. Mechanisms and measurements. Harvard University Press, Cambridge, MA.

Mosher, J. A., and C. J. Henny. 1976. Thermal adaptiveness of plumage color in screech owls. Auk 93:614-619.

Mundy, N. I. 2005. A window on the genetics of evolution: MC1R and plumage colouration in birds. Proceedings of the Roval Society B 272: $1633-1640$
Ozeki, H., S. Ito, K. Wakamatsu, and A. J. Thody. 1996. Spectrophotometric characterization of eumelanin and pheomelanin in hair. Pigment Cell Research 9:265-270.

Palma, A. T., and R. S. Steneck. 2001. Does variable coloration in juvenile marine crabs reduce risk of visual predation? Ecology 82:29612967.

Piersma, T., and J. Drent. 2003. Phenotypic flexibility and the evolution of organismal design. Trends in Ecology and Evolution 18: 228-233.

Pigliucci, M., and K. Preston. 2004. Phenotypic integration: studying the ecology and evolution of complex phenotypes. Oxford University Press, Oxford.

Porter, W. P. 1967. Solar radiation through the living body walls of vertebrates with emphasis on desert reptiles. Ecological Monographs 87:273-296.

Poston, J. P., D. Hasselquist, I. R. K. Stewart, and D. F. Wesneat. 2005. Dietary amino acids influence plumage traits and immune responses of male house sparrows, Passer domesticus, but not as expected. Animal Behaviour 70:1171-1181.

Quinteiro-Filho, W. M., A. Ribeiro, V. Ferraz-de-Paula, M. L. Pinheiro, M. Sakai, L. R. Sa, A. J. Ferreira, and J. Palermo-Neto. 2010. Heat stress impairs performance parameters, induces intestinal injury, and decreases macrophage activity in broiler chickens. Poultry Science 89:1905-1914.

Robbins, C. R. 2012. Bleaching and oxidation of human hair. Pages 263 328 in C. R. Robbins, ed. Chemical and physical behavior of human hair. Springer, Berlin.

Rosenblum, E. B. 2005. The role of phenotypic plasticity in colour variation of Tularosa basin lizards. Copeia 2005:586-596.

Roulin, A., R. Altwegg, H. Jensen, I. Steinslands, and M. Schaub. 2010 Sex-dependent selection on an autosomal melanic female ornament promotes the evolution of sex ratio bias. Ecology Letters 13:616-626.

Salaberría, C., P. Celis, I. López-Rull, and D. Gil. 2014. Effects of temperature and nest heat exposure on nestling growth, dehydration and survival in a Mediterranean hole-nesting passerine. Ibis 156: 265-275.

Siegel, H. S. 1980. Physiological stress in birds. BioScience 30:529-534.

Sirkia, P. M, M. Virolainen, and T. Laaksonen. 2010. Melanin coloration has temperature-dependent effects on breeding performance that may maintain phenotypic variation in a passerine bird. Journal of Evolutionary Biology 23:2385-2396.

Skolbekken, R., and A. C. Utne-Palm. 2001. Parental investment of male two-spotted goby, Gobiusculus flavescens (Fabricius). Journal of Experimental Marine Biology and Ecology 261:137-157.

Sköld, H. N., S. Aspengren, and M. Wallin. 2013. Rapid color change in fish and amphibians - function, regulation, and emerging applications. Pigment Cell and Melanoma Research 26:29-38.

Tarka, M., M. Åkesson, D. Hasselquist, and B. Hansson. 2014. Intralocus sexual conflict over wing length in a wild migratory bird. American Naturalist 183:62-73.

Tattersall, G. J., B. J. Sinclair, P. C. Withers, P. A. Fields, F. Seebacher, C. E. Cooper, and S. K. Maloney. 2012. Coping with thermal challenges: physiological adaptations to environmental temperatures. Comprehensive Physiology 2:2151-2202.

Telemeco, R. S. 2014. Immobile and mobile life-history stages have different thermal physiologies in a lizard. Physiological and Biochemical Zoology 87:203-215.

Temeles, E. J., I. L. Pan, J. L. Brennan, and J. N. Horwitt. 2000. Evidence for ecological causation of sexual dimorphism in a hummingbird. Science 289:441-443. 
Tobin, D. J., and S. Kauser. 2005. Hair melanocytes as neuro-endocrine sensors - pigments for our imagination. Molecular Cell Endocrinology 243:1-11.

Tuma, M. C, A. Zill, N. Le Bot, I. Vernos, and V. Gelfand. 1998. Heterotrimeric kinesin II is the microtubule motor protein responsible for pigment dispersion in Xenopus melanophores. Journal of Cell Biology 143:1547-1558.

Wakamatsu, K., S. Ito, and J. L. Rees. 2002. The usefulness of 4-amino3-hydroxyphenylalanine as a specific marker of pheomelanin. Pigment Cell Research 15:225-232.

Wakamatsu, K., Y. Nakanishi, N. Miyazaki, L. Kolbe, and S. Ito. 2012. UVA-induced oxidative degradation of melanins: fission of indole moiety in eumelanin and conversion to benzothiazole moiety in pheomelanin. Pigment Cell and Melanoma Research 25:434-445.

Walsberg, G. E., G. Campbell, and J. King. 1978. Animal coat color and radiative heat gain: a re-evaluation. Journal of Comparative Physiology B 126:211-222.

Walsberg, G. E., and B. O. Wolf. 1995. Effects of solar radiation and wind speed on metabolic heat production by two mammals with contrasting coat colours. Journal of Experimental Biology 198:14991507.

Ward, J. M., J. D. Blount, G. D. Ruxton, and D. C. Houston. 2002. The adaptive significance of dark plumage for birds in desert environments. Ardea 90:311-323.

Watt, W. B. 1968. Adaptive significance of pigment polymorphisms in Colias butterflies. I. Variation of melanin pigment in relation to thermoregulation. Evolution 22:437-458.

West, P. M., and C. Packer. 2002. Sexual selection, temperature, and the lion's mane. Science 297:1339-1343.
West-Eberhard, M. J. 2003. Developmental plasticity and evolution. Oxford University Press, Oxford.

White, G. C., and K. P. Burnham. 1999. Program MARK: survival estimation from populations of marked animals. Bird Study 46:S120-S139.

Wilson, R. S., and C. E. Franklin. 2002. Testing the beneficial acclimation hypothesis. Trends in Ecology and Evolution 17:66-70.

Wingfield, J. C., J. P. Smith, and D. S. Farner. 1982. Endocrine responses of white-crowned sparrows to environmental stress. Condor 84:399409.

Wink, M., H. Sauer-Gürth, F. Martínez, G. Doval, G. Blanco, and O. Hatzofe. 1998. The use of (GACA)4-PCR to sex old world vultures (Aves: Accipitridae). Molecular Ecology 7:779-782.

Witte, F., C. D. N. Barel, and R. J. C. Hoogerhoud. 1990. Phenotypic plasticity of anatomical structures and its ecomorphological significance. Netherland Journal of Zoology 40:278-298.

Wittkopp, P. J., and P. Beldade. 2009. Development and evolution of insect pigmentation: genetic mechanisms and the potential consequences of pleiotropy. Seminars in Cell and Developmental Biology 20:65-67.

Xirouchakis, S. M., and M. Mylonas. 2007. Breeding behaviour and parental care of the griffon vulture Gyps fulvus on the island of Crete (Greece). Ethology Ecology and Evolution 19:1-26.

Zeuss, D., R. Brandl, M. Brändle, C. Rahbek, and S. Brunzel. 2014. Global warming favours light-coloured insects in Europe. Nature Communications 5:3874.

Zink, R. M., and J. V. Remsen. 1986. Evolutionary processes and patterns of geographic variation in birds. Current Ornithology 4:1-69.

Editor: Yannis Michalakis
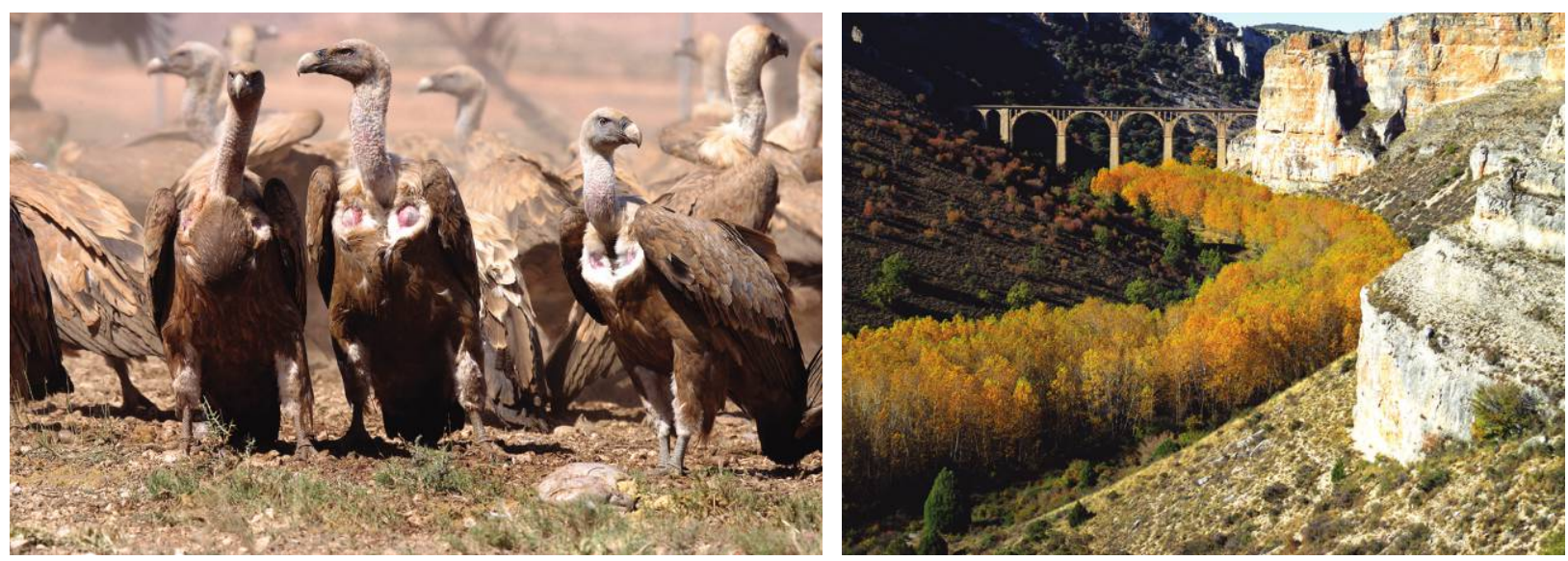

Left, adult griffon vultures Gyps fulvus. Photo: Alberto Carreño. Right, Hoces del Riaza Natural Park. Photo: Juan A. Fargallo. 